WSRC-TR-2001-00428, REV. 0

Key Words:

XAFS

Sludge

Uranium

Mercury

Retention:

Permanent

\title{
Determination of Uranium and Mercury Speciation in High Level Waste Tank 8F and 11 H Sludge
}

Martine C. Duff, Douglas B. Hunter, Mark J. Barnes and Samuel D. Fink

REPORT DATE SEPTEMBER 24, 2001

Westinghouse Savannah River Company

Savannah River Site

Aiken, SC 29808

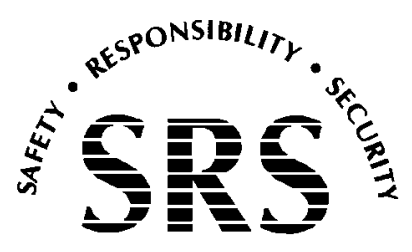

SAVANNAH RIVER SITE

Prepared for the U.S. Department of Energy Under

Contract Number DE-AC09-96SR18500 
This document was prepared in conjunction with work accomplished under Contract No. DE-AC09-96SR18500 with the U.S. Department of Energy.

\section{DISCLAIMER}

This report was prepared as an account of work sponsored by an agency of the United States Government. Neither the United States Government nor any agency thereof, nor any of their employees, makes any warranty, express or implied, or assumes any legal liability or responsibility for the accuracy, completeness, or usefulness of any information, apparatus, product or process disclosed, or represents that its use would not infringe privately owned rights. Reference herein to any specific commercial product, process or service by trade name, trademark, manufacturer, or otherwise does not necessarily constitute or imply its endorsement, recommendation, or favoring by the United States Government or any agency thereof. The views and opinions of authors expressed herein do not necessarily state or reflect those of the United States Government or any agency thereof.

This report has been reproduced directly from the best available copy.

Available for sale to the public, in paper, from: U.S. Department of Commerce, National Technical Information Service, 5285 Port Royal Road, Springfield, VA 22161

phone: (800) 553-6847

fax: (703) 605-6900

email: orders@ntis.fedworld.gov

online ordering: http://www.ntis.gov/support/index.html

Available electronically at http://www.doe.gov/bridge

Available for a processing fee to U.S. Department of Energy and its contractors, in paper, from: U.S. Department of Energy, Office of Scientific and Technical Information, P.O. Box 62, Oak Ridge, TN 37831-0062

phone: (865)576-8401

fax: $(\mathbf{8 6 5}) 576-5728$

email: reportseadonis.osti.gov 
Key Words:

XAFS

Sludge

Uranium

Retention:

Permanent

\title{
Determination of Uranium and Mercury Speciation in High Level Waste Tank 8F and 11H Sludge
}

\author{
Martine C. Duff \\ Douglas B. Hunter \\ Mark J. Barnes, and \\ Samuel D. Fink
}

REPORT DATE: SEPTEMBER 24, 2001

Westinghouse Savannah River Company

Savannah River Site

Aiken, SC 29808

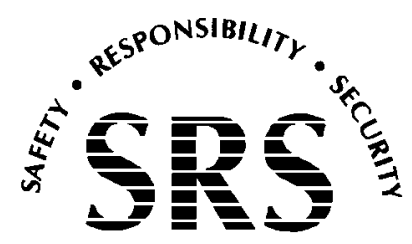

SAVANNAH RIVER SITE

Prepared for the U.S. Department of Energy Under

Contract Number DE-AC09-96SR18500 


\section{REVIEWS AND APPROVALS}

M. C. Duff, Author, Waste Processing Technology

Date

D. B. Hunter, Author, Nonproliferation Technology

Date

M. J. Barnes, Author, Waste Processing Technology

Date

S. D. Fink, TFA Lead and Level 4 Manager, Waste Processing Technology

Date

R. E. Edwards, Manager, Process Engineering

Date

J. T. Carter, Director of Engineering, SWPF

Date

W. L. Tamosaitis, Manager, Waste Processing Technology

Date

M. C. Thompson, Design Check, Actinide Technology

Date

Page 1 of 33 


\section{TABLE OF CONTENTS}

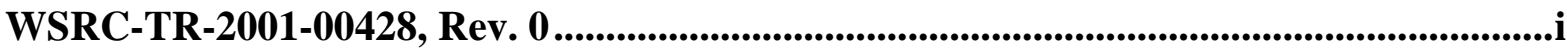

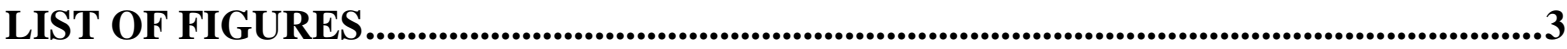

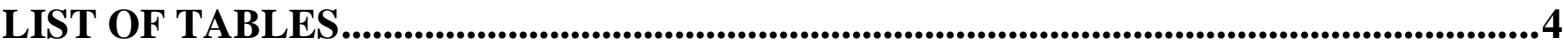

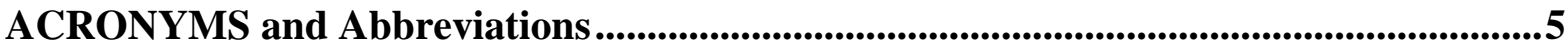

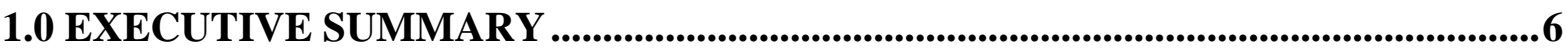

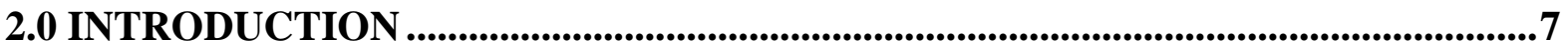

2.1 Use of XAFS Techniques .........................................................................................................

2.2 Experimental Objectives...........................................................................................................7

3.0 MATERIALS AND EXPERIMENTAL METHODS ...................................................8

3.1 Sample Preparation ...................................................................................................... 8

3.2 Sample Shielding ................................................................................................................14

3.2.1 XANES and EXAFS Data Collection............................................................................15

3.2.1.1 Studies Conducted at the National Synchrotron Light Source.......................15

3.2.2 EXAFS Data Analyses .....................................................................................................18

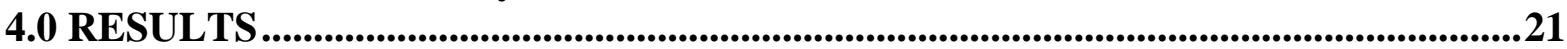

4.1.1 Background on the Characterization of U Solids with XAFS ...............................21

4.2 EXAFS Analyses.......................................................................................................................21

4.2.1 Raw Energy Scan and Chi Data for the $U$ in the Tank 8F Sludge......................21

4.2.2 Normalized Energy Scan and Chi Data for $\mathrm{Hg}$ in the Tank 11H Sludge ...........21

4.2.3 Fourier-Transformed Data .........................................................................................22

4.2.3.1 Fourier-Transformed and Model Fit Data for $U$ in the Tank 8F Sludge....24

4.2.3.2 Model Fits in Chi Space for the $U$ in the Tank 8F Sludge Sample ..............27

4.2.3.3 Mercury Fourier Transform and Model Fit Data for $\mathrm{Hg}$ in the Tank 11H

Sludge Sample................................................................................................................................22

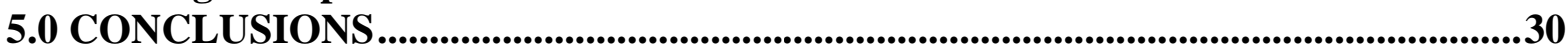

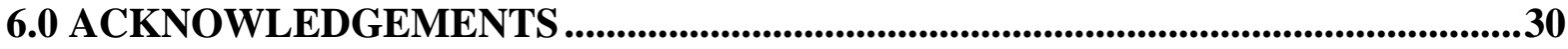

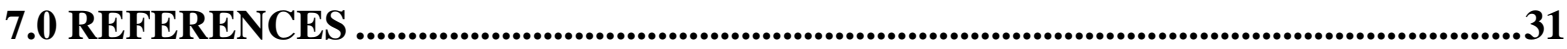


WSRC-TR-2001-00428, REV. 0

\section{LIST OF FIGURES}

Figure 3-1 Diagram showing the design used to embed the HLW sludge samples that we analyzed using XAFS techniques.

Figure 3-2 Images of the preparation of freshly-poured sludge samples. One side of the plastic frame was poured first.

Figure 3-3 Swiping the samples after curing. All sludge samples were free of contamination when they cured.

Figure 3-4 Two images of the HLW sludge samples that we tested for several months in the embedding resin. Arrows show evidence of gas generation (i.e., bubbles)..................... 13

Figure 3-5 Overhead digital image of the aluminum box, which provided shielding during our analyses. The box contains a series of guillotine doors that can be raised and removed during the XAFS data collection.

Figure 3-6 Image of the inner portion of the sample box, which shows closed guillotine doors. The inner portion of the box is visible through a plastic rendition of the outer $\mathrm{Al}$ metal box. X-ray invisible brown kapton film and tape comprise the primary window in the front of the largest guillotine door.

Figure 3-7 View of the Al sample box outside of its primary box with all three of the guillotine doors open.

Figure 3-8 Diagram of the downstream portion of the hutch table at NIST beamline X23a2 (not drawn to scale).

Figure 3-9 Image of the hutch table (looking upstream toward the entrance of the X-ray source) showing the linkage of the 13-element detector to the Lytle Detector box, which is in line with the X-ray beam.

Figure 3-10 Setting up the 13-element detector at the NSLS. The large screen on the detector shows the raw X-ray fluorescence signal coming from the sample.

Figure 3-11 The main window containing the output from the mass channel analyzer for the

13-element detector.

Figure 4-1 Raw U EXAFS spectra for U in the HLW Tank 8F sludge...............................22

Figure 4-2 The $k^{2}$-weighted chi data (the plot of the wavevector in reciprocal space) for $\mathrm{U}$ in the Tank $8 \mathrm{~F}$ sludge. 22

Figure 4-3 Normalized Hg-XAFS spectra for $\mathrm{Hg}$ in the HLW Tank 11H sludge. The HgO spectra are from Duff et al. (2000).

Figure 4-4 The $k^{2}$-weighted chi data for $\mathrm{Hg}$ in the Tank $11 \mathrm{H}$ sludge. ................................ 23

Figure 4-5 FT RDF and first shell model fit data for $U$ in the Tank 8F sludge- uncorrected for phase shift.

Figure 4-6 FT data and multiple shell modeling results for the $\mathrm{U}$ in the HLW sludge Tank 8F sample-uncorrected for phase shift.

Figure 4-7 Fourier-filtered data for $U$ in the Tank $8 F$ sludge. The unfiltered chi data for $U$ are shown with the back transformed data from the multishell fits in $\mathrm{R}$ space................27

Figure 4-8 FT EXAFS data and model fit data for $\mathrm{Hg}$ in the Tank $11 \mathrm{H}$ sludge sample-

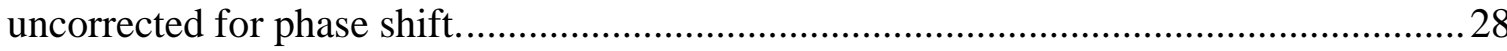

Figure 4-9 Fourier-filtered data for $\mathrm{Hg}$ in the Tank $11 \mathrm{H}$ sludge. The unfiltered chi data for $\mathrm{Hg}$ are shown with the back transformed data from the first shell fits in $\mathrm{R}$ space. Fits for the $\mathrm{Hg}$ were not of the same quality as those for the $\mathrm{U}$ in Tank $8 \mathrm{~F}$ sludge. 


\section{LIST OF TABLES}

Table 3-1 Characterization data for Tank $11 \mathrm{H}$ sludge. The Fe, $\mathrm{Mn}, \mathrm{Ca}$ and $\mathrm{Hg}$ data were acquired by ICP-MS. Remaining data were acquired by ICP-emission spectrometry (ICP-

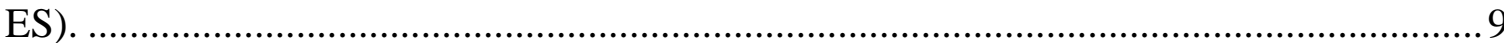

Table 3-2 Levels of radioisotopes in Tank 11H sludge....................................................... 9

Table 3-3 Characterization data for Tank 8F sludge....................................................... 9

Table 3-4 Levels of some of the radioisotopes in Tank 8F sludge. Data supplied by Ned Bibler of SRTC

Table 3-5 The U and Pu isotopes in Tank 8F Sludge. Data supplied by Ned Bibler of SRTC.

Table 4-1 Fit results for the U in the HLW Tank 8F sludge sample (performed in R space). The magnitude of the Debye-Waller Factor [represented as $\left.\sigma^{2}[\AA]^{2}\right]$ indicates the variation of the bond length determination (or spread but not error). It also provides information on goodness of fit-for example, a negative value would indicate a poor fit. .26

Table 4-2 Fit results for the Hg in the HLW Sludge Tank 11H sample (performed in R space). The magnitude of the Debye-Waller Factor [represented as $\left.\sigma^{2}[\AA]^{2}\right]$ indicates the variation of the bond length determination (or spread but not error). It also provides information on goodness of fit-for example, a negative value would indicate a poor fit. 


\section{ACRONYMS AND ABBREVIATIONS}

$\mathrm{CN}$

$\delta(\mathrm{K})$

EXAFS

$\mathrm{E}$

$\mathrm{E}_{0}$

$\mathrm{E}_{0}$ Shift

$\mathrm{F}$

FEFF

FFIT

FT

FT-IR

h

$\mathrm{Hg}$

HLW

$k$

$\mathrm{m}$

MSR

NSLS

$\mathrm{O}$

Oax

Oeq

R-space

RDF

Rotate_Atoms

$\mathrm{S} / \mathrm{N}$

$\mathrm{S} 0 \wedge 2$ or $\mathrm{S}_{0}^{2}$

$\sigma^{2}$ or $\mathrm{SIGMA}^{2}$

SRTC

U

WSRC

XAFS

XANES

XRD
Coordination number

Electronic phase shifts due to atomic potentials

Extended X-ray Absorption Fine-Structure

$E$ is the kinetic energy of the photoelectron

EXAFS defined edge energy in electron volts or eV (not equal to edge energy as defined by XANES but is equal to the energy of the photoelectron at $k=0$.

A relative value of $E_{0}$ (a variable in the EXAFS Equation)

Back scattering amplitude of the atom

An automated computer program for making ab initio multiple scattering calculations of XAFS and XANES spectra for atoms.

A Levenberg-Marquardt fitting program created by researchers at the University of Washington

Fourier-transform

Fourier-transform Infrared (Spectroscopy)

Plank's constant

Mercury

High Level Waste

Chi where $k$ is the square root of $\left[\left(2 \mathrm{~m} / \hbar^{2}\right) *\left(\mathrm{E}-\mathrm{E}_{0}\right)\right]$

Mass of the photoelectron

Multiple Scattering Resonances

National Synchrotron Light Source

Oxygen

Axial actinide-oxygen bond

Equatorial actinide-oxygen bond

$\mathrm{R}$-space pertains to mean atom position or bond distance (radial

distance in $\AA$ )

Radial Distribution Function

A program that generates Cartesian coordinate information for atoms from radial distance values.

Signal to Noise

Amplitude reduction factor (an EXAFS equation variable associated

with central atom shake-up and shake-off effects)

Debye-Waller Factor or Relative Mean Square Disorder in bond length

(a variable in the EXAFS Equation)

Savannah River Technology Center

Uranium

Westinghouse Savannah River Company

X-ray Absorption Fine-Structure (XANES plus EXAFS)

X-ray Absorption Near-Edge Structure

X-ray Diffraction 


\subsection{EXECUTIVE SUMMARY}

Our study used synchrotron-based X-ray absorption fine-structure spectroscopy (XAFS) and molecular modeling to characterize the chemistry of metals in HLW sludge. This report discusses our first measurements of metal speciation in HLW samples. This original focus of this work was to obtain information on the noble metal speciation in the tank waste with XAFS techniques. However, we were unable to detect the noble metals in the waste due to limited sample mass allowed and spectral interference (mainly from X-ray scattering). In this report, we also discuss the technology that we developed to safely contain and study these materials at another DOE facility (the National Synchrotron Light Source, Brookhaven National Lab., NY). We investigated the bonding environment of uranium (Tank 8F) and mercury (Tank 11H) in two sludge samples. Our report yields the following conclusions for these two samples.

- In Tank 8F, most of the $\mathrm{U}$ is present as a U(VI) oxyhydroxide precipitate that contains $\mathrm{U}$ in the second coordination shell.

- About $5 \%$ of the $\mathrm{U}$ in the Tank $8 \mathrm{~F}$ sludge exists as gamma-uranium metal. This type of $\mathrm{U}$ metal requires a high temperature to form and its presence indicates that the fuel rod dissolution was not complete or that $U$ metal filings may have been added to the waste. Our estimates of the percentage of $U$ metal in this sample are conservatively low. The presence of $U$ metal is probably not a criticality issue because the source of the filings was most likely depleted $U$ metal. Also, these findings represent a single sample from the tank.

- Although Tank $8 \mathrm{~F}$ is rich in Fe oxides, we did not observe Fe in the local coordination environment of the $\mathrm{U}$-suggesting the sludge $\mathrm{U}$ is not sorbed or (co) precipitated with $\mathrm{Fe}$ oxides in the sludge.

- Mercury in Tank $11 \mathrm{H}$ is present in an oxidized form like $\mathrm{Hg}$ (II) oxide. No metallic $\mathrm{Hg}$ forms were detected. These results indicate the quantity of formic acid (used to reduce $\mathrm{Hg}$ to metallic $\mathrm{Hg}$ and acidify the waste prior to vitirification) should be added in stoichiometric excess prior to vitirification as consistent with current operations.

- The approach we developed to analyze the HLW sludge samples using XAFS spectroscopic techniques can be applied to similar or other radioactive samples.

The following report details the approach we took to obtain the information on the metals ( $\mathrm{U}$ and $\mathrm{Hg}$ ) in the two HLW sludge samples. 


\subsection{INTRODUCTION}

Little information exists on actinide speciation in high level waste (HLW). This information is applicable to HLW tank decontamination and treatment and to environmental risk assessment. For example, if uranium (U) is present as metallic U metal, the mobility of the $\mathrm{U}$ is lower than if the $\mathrm{U}$ is present as an oxidized and more soluble form such as a sodium $\mathrm{U}(\mathrm{VI})$ hydroxide solid. We do not expect significant portions of the $\mathrm{U}$ to be present in the metallic form because the HLW is the result of spent fuel dissolution, which is an oxidizing process. As for $\mathrm{Hg}$, information on the $\mathrm{Hg}$ compounds may provide insight as to whether the $\mathrm{Hg}$ forms are explosive. Uranium characterization information has potential applications to criticality and neutron poisons and to the identification of contaminant source terms to groundwater for leaking tanks. Additionally, an improved understanding of metal speciation can aid in optimizing glass stability and vitrification through knowledge of what forms of metals are present in the waste [for example, $\mathrm{Cr}(\mathrm{VI})$ is more detrimental to glass stability than $\mathrm{Cr}(\mathrm{III})]$.

\subsection{Use of XAFS Techniques}

The local environment of metals associated with surfaces can be investigated with analytical techniques such as X-ray absorption fine-structure (XAFS) spectroscopy. We used XAFS to study the local structural environment of $\mathrm{U}$ and $\mathrm{Hg}$ in HLW sludge samples. The XAFS spectroscopic techniques are among the best for providing detailed chemical speciation information in environmental samples_-particularly when information from multiple characterization techniques is available. The term XAFS is applicable to both X-ray absorption near-edge structure (XANES) and extended X-ray absorption fine-structure (EXAFS) spectroscopic techniques. The XAFS spectra give robust local structural information on coordination number $(\mathrm{CN})$, bonding symmetry, neighbor and near-neighbor atomic distances and bond disorder (as the root mean square deviations of distances about the average values). Additionally, the information gained is atom specific-making it a versatile technique for structural determinations of atom clusters. ${ }^{1,2}$ EXAFS spectroscopy in particular has been successfully applied to the structural elucidation of metal solids and sorbed metals on surfaces because the technique does not require long range order (i.e., periodicity) or crystalline samples.

\subsection{Experimental Objectives}

The primary objective of this research was to obtain information on the speciation of metals in HLW sludge from the SRS. Prior to this preliminary study, little information was available on the local structural speciation of metals in these materials. Two dried HLW sludge samples from Tank 8F and $11 \mathrm{H}$ were prepared for these analyses. We used XAFS techniques to obtain information on the average local structural speciation of the uranium (Tank $8 \mathrm{~F}$ ) and mercury (Tank $11 \mathrm{H}$ ) such as $\mathrm{CN}$, geometry, near and next-nearest neighbor environment of the target metal. To evaluate whether our results were realistic, we used molecular models to test the findings from our EXAFS studies. 


\subsection{MATERIALS AND E XPERIMENTAL METHODS}

Samples were prepared for XAFS analyses. The details of the sample preparation, XAFS data collection and data analyses are presented below.

\subsection{Sample Preparation}

Testing required the preparation of 20-mg quantities of HLW sludge samples from Tanks $8 \mathrm{~F}$ and $11 \mathrm{H}$. Michael Poirier of SRTC supplied the sludge samples. Sludge $8 \mathrm{~F}$ was dried in an oven at $100{ }^{\circ} \mathrm{C}$ prior to use because it was in a slurry form. Sludge $11 \mathrm{H}$ was dry upon receipt. Characterization data for sludge $8 \mathrm{~F}$ are supplied by Barnes et al. (1998) ${ }^{3}$

whereas data for sludge $11 \mathrm{H}$ are supplied in Hobbs et al. (1998). ${ }^{4}$ The sludge solids were not rinsed with inhibited water as customary in other studies to remove some of the salts because rinsing could potentially alter the speciation of the metals. Once dried, the sludge samples were embedded in a polysytrene resin according to the method described in Figures 3-1 and 3-2. The sample was placed on top of the dried resin and then the remainder of the resin was poured. The samples were wrapped in Parafilm ${ }^{\circledR}$ to keep them contamination-free during the final embedding. The Parafilm ${ }^{\circledR}$ pulled away freely after the resin cured. Prior to the XAFS studies, we performed previous testing of the resin with 20-mg quantities of real HLW sludge samples to determine that the polystyrene resin provided suitable containment. The testing of the embedded sludge samples was required to satisfy the safety and health physics requirements of the synchrotron facility at Brookhaven National Laboratory.

The polystyrene was tested for suitability with real HLW (Figure 3-3 and Figure 3-4). Upon close examination, the samples showed evidence of pressurization due to gas generation. However, slight gas generation was observed after 60 days of embedding. Bubbles are most evident in image B. However, continued visual observation and swiping of these samples for a period of 5 months indicated that the embedded samples did not breach their containment. To reduce risks of sample breaching, we chose to work with freshly embedded samples at NSLS. 
Table 3-1 Characterization data for Tank $11 \mathrm{H}$ sludge. The Fe, $\mathrm{Mn}, \mathrm{Ca}$ and $\mathrm{Hg}$ data were acquire by ICP-MS. Remaining data were acquired by ICP-emission spectrometry (ICP$\mathrm{ES}){ }^{4}$

\begin{tabular}{|c|c|c|}
\hline Sludge Species & wt \% & $\begin{array}{c}\text { Amount of Element } \\
\text { in mg in a 20-mg } \\
\text { Sample }\end{array}$ \\
\hline $\mathrm{Fe}$ & 18.4 & 3.7 \\
\hline $\mathrm{Na}$ & 9.37 & 1.88 \\
\hline $\mathrm{Al}$ & 24.6 & 4.92 \\
\hline $\mathrm{Mn}$ & 10.0 & 2 \\
\hline $\mathrm{Ca}$ & 1.50 & 0.3 \\
\hline $\mathrm{Si}$ & 0.88 & 0.17 \\
\hline $\mathrm{Hg}$ & 0.40 & 0.08 \\
\hline
\end{tabular}

Table 3-2 Levels of radioisotopes in Tank $11 \mathrm{H}$ sludge. ${ }^{4}$

\begin{tabular}{|c|c|c|}
\hline Sludge Species & nCi $^{-\mathbf{1}}$ & $\begin{array}{c}\text { Amount of } \boldsymbol{\mu C i} \text { in a } \\
\text { 20-mg Sample }\end{array}$ \\
\hline Sr90 & Below detection limits & Below detection limits \\
\hline Cs137 & $1.04 \mathrm{E}+06$ & 2.08 \\
\hline Am241 & $3.10 \mathrm{E}+04$ & 0.062 \\
\hline Eu154 & $1.65 \mathrm{E}+05$ & 3.3 \\
\hline Co60 & $1.92 \mathrm{E}+03$ & 0.0384 \\
\hline Eu155 & $1.65 \mathrm{E}+05$ & 0.582 \\
\hline Pu-239/240 & Below detection limits & Below detection limits \\
\hline Pu-238/241 & $9.31 \mathrm{E}+05$ & 1.862 \\
\hline
\end{tabular}

Table 3-3 Characterization data for Tank $8 \mathrm{~F}$ sludge. ${ }^{3}$

\begin{tabular}{|c|c|c|}
\hline Sludge Species & wt \% & $\begin{array}{c}\text { Amount of Element in } \\
\text { mg in a 20-mg Sample }\end{array}$ \\
\hline $\mathrm{Fe}$ & 19.3 & 3.86 \\
\hline $\mathrm{Na}$ & 11.8 & 2.36 \\
\hline $\mathrm{Al}$ & 3.01 & 0.602 \\
\hline $\mathrm{Mn}$ & 3.75 & 0.75 \\
\hline $\mathrm{Ca}$ & 1.52 & 0.304 \\
\hline $\mathrm{Si}$ & 1.00 & 0.2 \\
\hline $\mathrm{Ni}$ & 3.78 & 0.756 \\
\hline $\mathrm{Hg}$ & 0.46 & 0.092 \\
\hline
\end{tabular}


Table 3-4 Levels of some of the radioisotopes in Tank 8F sludge. Data supplied by Ned Bibler of SRTC.

\begin{tabular}{|c|c|c|c|}
\hline Sludge Species & wt \% & $\mu \mathbf{C i ~ \mathbf { g } ^ { - 1 }}$ & $\begin{array}{c}\text { Amount of } \boldsymbol{\mu C i} \text { in a 20- } \\
\text { mg Sample }\end{array}$ \\
\hline Sr-90 & $3.3 \mathrm{E}-05$ & $4.5 \mathrm{E}+03$ & 90 \\
\hline Cs-137 & $3.7 \mathrm{E}-04$ & $3.2 \mathrm{E}+02$ & 6.4 \\
\hline Am-241 & $1.9 \mathrm{E}-04$ & $6.6 \mathrm{E}+00$ & 0.132 \\
\hline Eu-154 & $1.5 \mathrm{E}-06$ & $4.0 \mathrm{E}+00$ & 0.08 \\
\hline Co-60 & $4.7 \mathrm{E}-07$ & $5.3 \mathrm{E}+00$ & 0.106 \\
\hline Eu-155 & $2.7 \mathrm{E}-07$ & $1.3 \mathrm{E}+00$ & 0.026 \\
\hline Np-237 & $1.6 \mathrm{E}-03$ & $1.1 \mathrm{E}-02$ & 0.00022 \\
\hline Am-243 & $3.0 \mathrm{E}-04$ & $6.0 \mathrm{E}-01$ & 0.012 \\
\hline
\end{tabular}

Table 3-5 The U and Pu isotopes in Tank 8F Sludge. Data supplied by Ned Bibler of SRTC.

\begin{tabular}{|c|c|c|c|c|}
\hline Sludge Species & wt \% & $\mu$ Ci $^{-1}$ & $\begin{array}{c}\text { \% Isotopic } \\
\text { Distribution }\end{array}$ & $\begin{array}{c}\text { Amount of } \mu \text { Ci } \\
\text { in a 20-mg } \\
\text { Sample }\end{array}$ \\
\hline U-233 (a) & $<2 \mathrm{E}-04$ & $<2 \mathrm{E}-02$ & $<0.003$ & $<0.0004$ \\
\hline $\mathbf{U - 2 3 4}$ & $2.8 \mathrm{E}-04$ & $1.8 \mathrm{E}-02$ & 0.005 & 0.00036 \\
\hline $\mathbf{U - 2 3 5}$ & $2.0 \mathrm{E}-02$ & $4.3 \mathrm{E}-04$ & 0.335 & 0.0000086 \\
\hline $\mathbf{U - 2 3 6}$ & $1.3 \mathrm{E}-03$ & $8.5 \mathrm{E}-04$ & 0.022 & 0.000017 \\
\hline U-238 & $5.9 \mathrm{E}+00$ & $2.0 \mathrm{E}-02$ & 99.627 & 0.0004 \\
\hline Total U & $5.9 \mathrm{E}+00$ & $2.0 \mathrm{E}-02$ & $\sim 100$ & 0.00077 \\
\hline Pu-238 (b) & $<3.5 \mathrm{E}-04$ & $<60$ & $<3.4$ & $<1.2$ \\
\hline Pu-239 & $9.1 \mathrm{E}-03$ & $5.7 \mathrm{E}+00$ & 88.8 & 0.114 \\
\hline Pu-240 & $6.1 \mathrm{E}-04$ & $1.4 \mathrm{E}+00$ & 5.9 & 0.028 \\
\hline Pu-241 & $1.3 \mathrm{E}-05$ & $1.4 \mathrm{E}+01$ & 0.1 & 0.28 \\
\hline Pu-242 & $1.7 \mathrm{E}-04$ & $6.6 \mathrm{E}-03$ & 1.7 & 0.000132 \\
\hline Total Pu & $1.0 \mathrm{E}-02$ & $\sim 20$ & $\sim 100$ & $\sim 0.4$ \\
\hline
\end{tabular}

(a) The concentration of U-233 was too low to be detected. This upper limit is based on the analytical method for U-233.

(b) This upper limit assumes that all the alpha activity detected was due to $\mathrm{Pu}-238$.

Based on analyses of other HLW slurries, only nominally $80 \%$ is due to $\mathrm{Pu}-238$. 


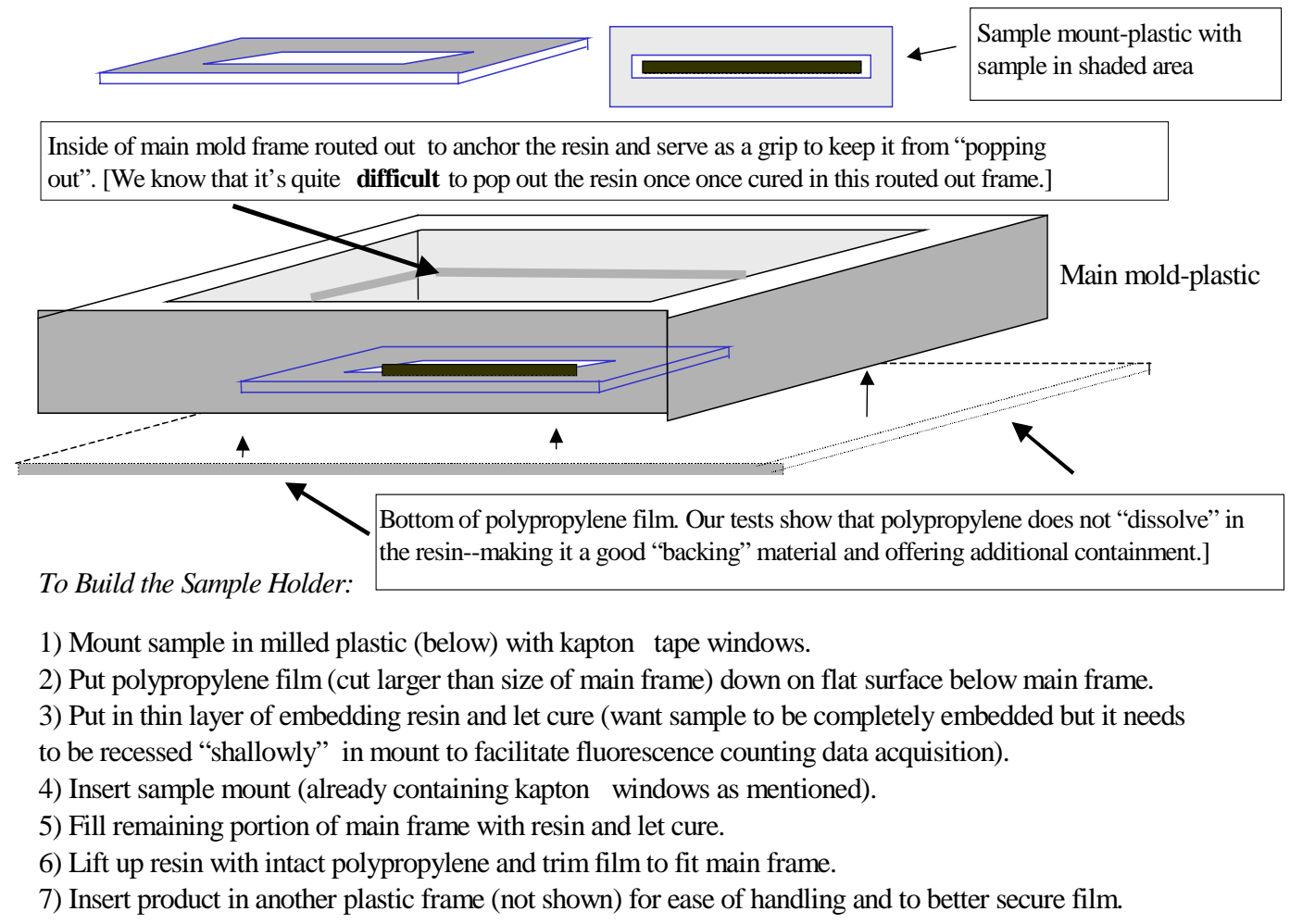

Figure 3-1 Diagram showing the design used to embed the HLW sludge samples that we analyzed using XAFS techniques. 


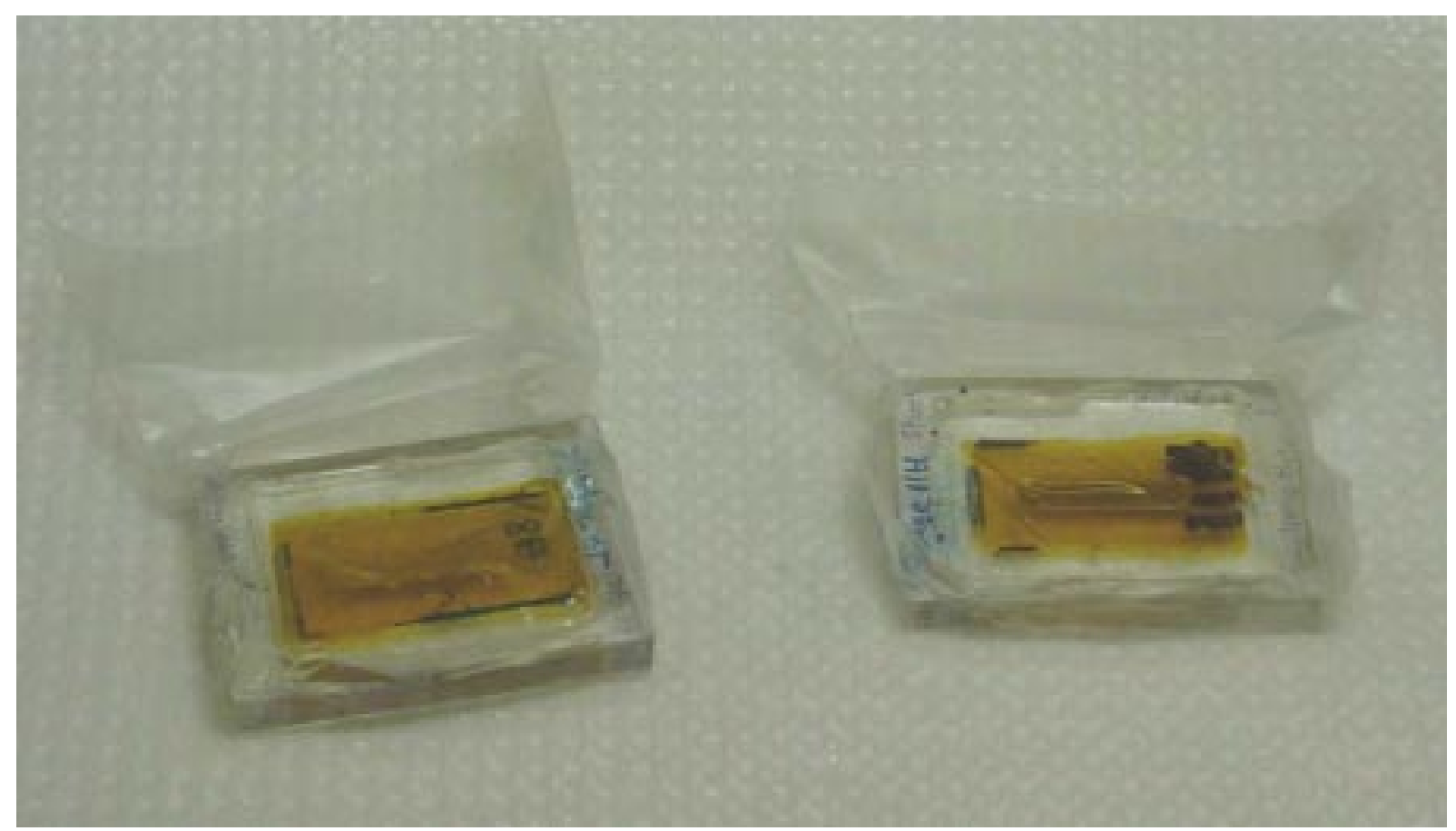

Figure 3-2 Images of the preparation of freshly-poured sludge samples. One side of the plastic frame was poured first.

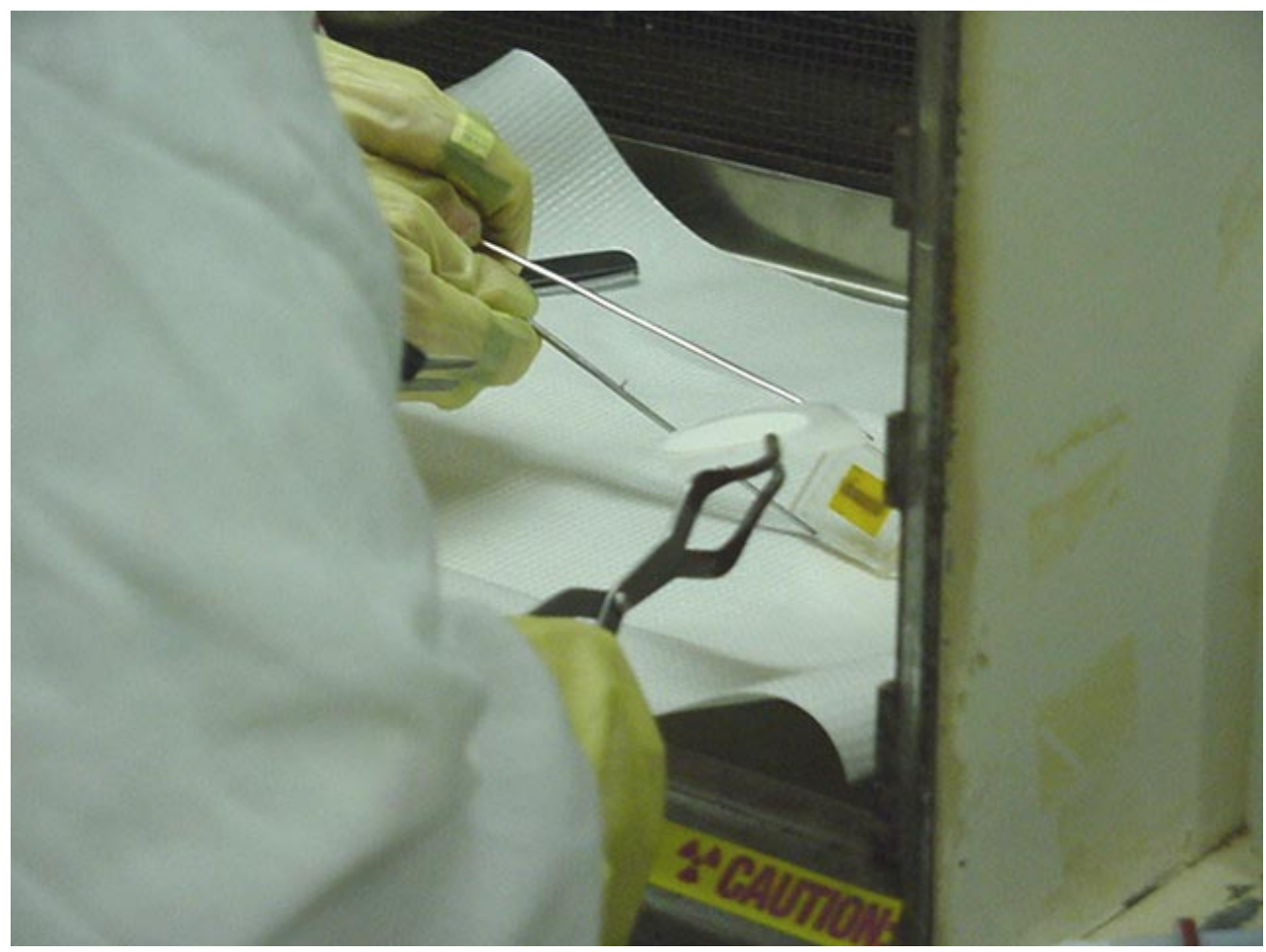

Figure 3-3 Swiping the samples after curing. All sludge samples were free of contamination when they cured.

Page 12 of 33 
WSRC-TR-2001-00428, REV. 0

A

B
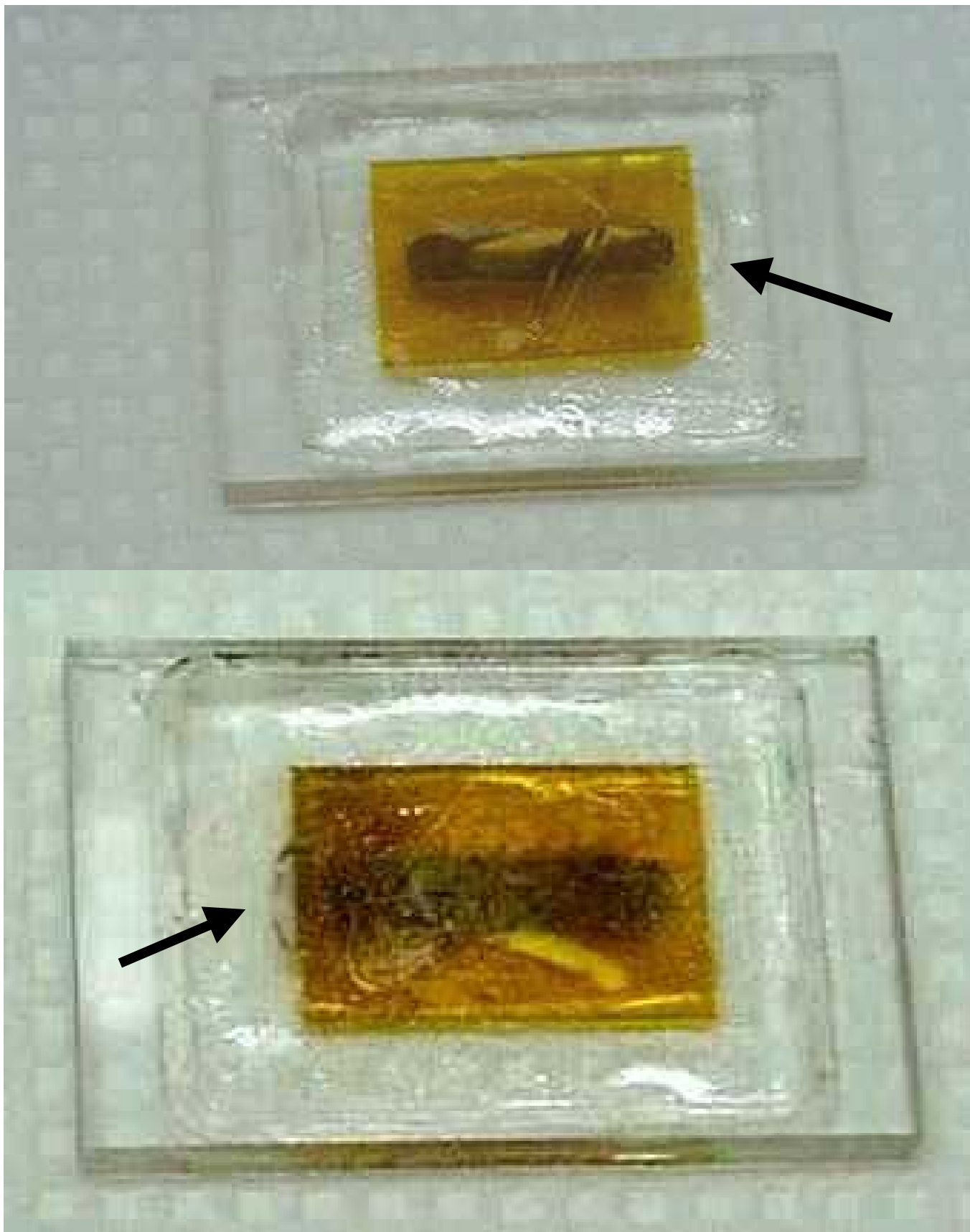

Figure 3-4 Two images of the HLW sludge samples that we tested for several months in the embedding resin. Arrows show evidence of gas generation (i.e., bubbles). 


\subsection{Sample Shielding}

The levels of strontium in the sludge produced high levels of beta radiation. Therefore, the samples had to be placed in two types of aluminum boxes. These two boxes were used during handling and one of the boxes was used during analyses at the synchrotron. The boxes were made of high purity (Grade 6061) aluminum because aluminum of lower grade would contain metals that give off bremstralung (gamma) radiation in the presence of high beta radiation. Pictures of the boxes are shown in Figure 3-5, Figure 3-6 and Figure 3-7. The first box shares its roof with the inner portion of the second box. The inner box lifts out of the outer box via the shared roof. This box sits in the Lytle detector, which has the same dimensions as the outer box. The embedded HLW sludge sample is inside a plastic zip-lock bag in a vertical position. A metal screw that penetrates through the Al box floor secures the bagged sludge sample.

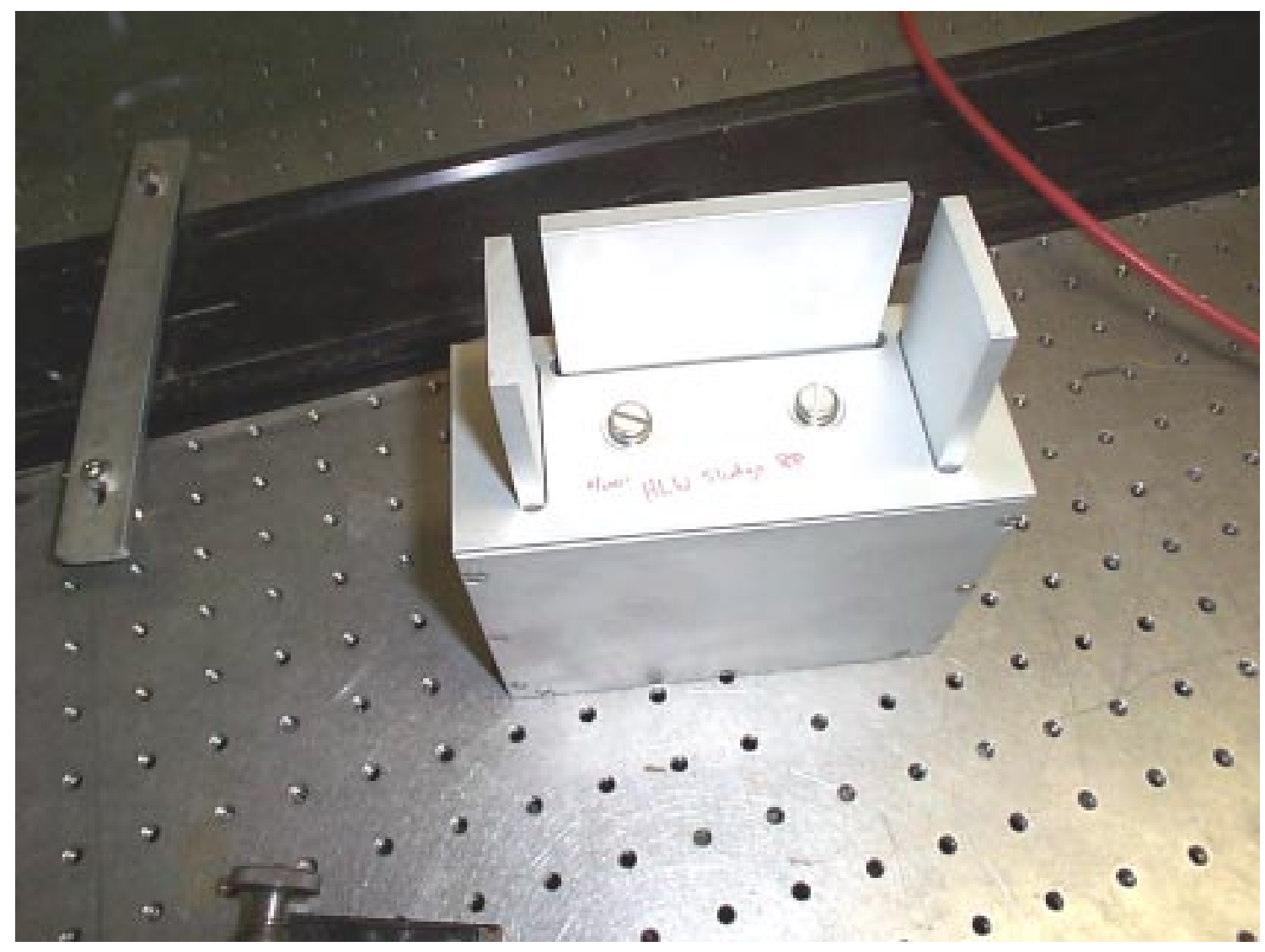

Figure 3-5 Overhead digital image of the aluminum box, which provided shielding during our analyses. The box contains a series of guillotine doors that can be raised and removed during the XAFS data collection. 


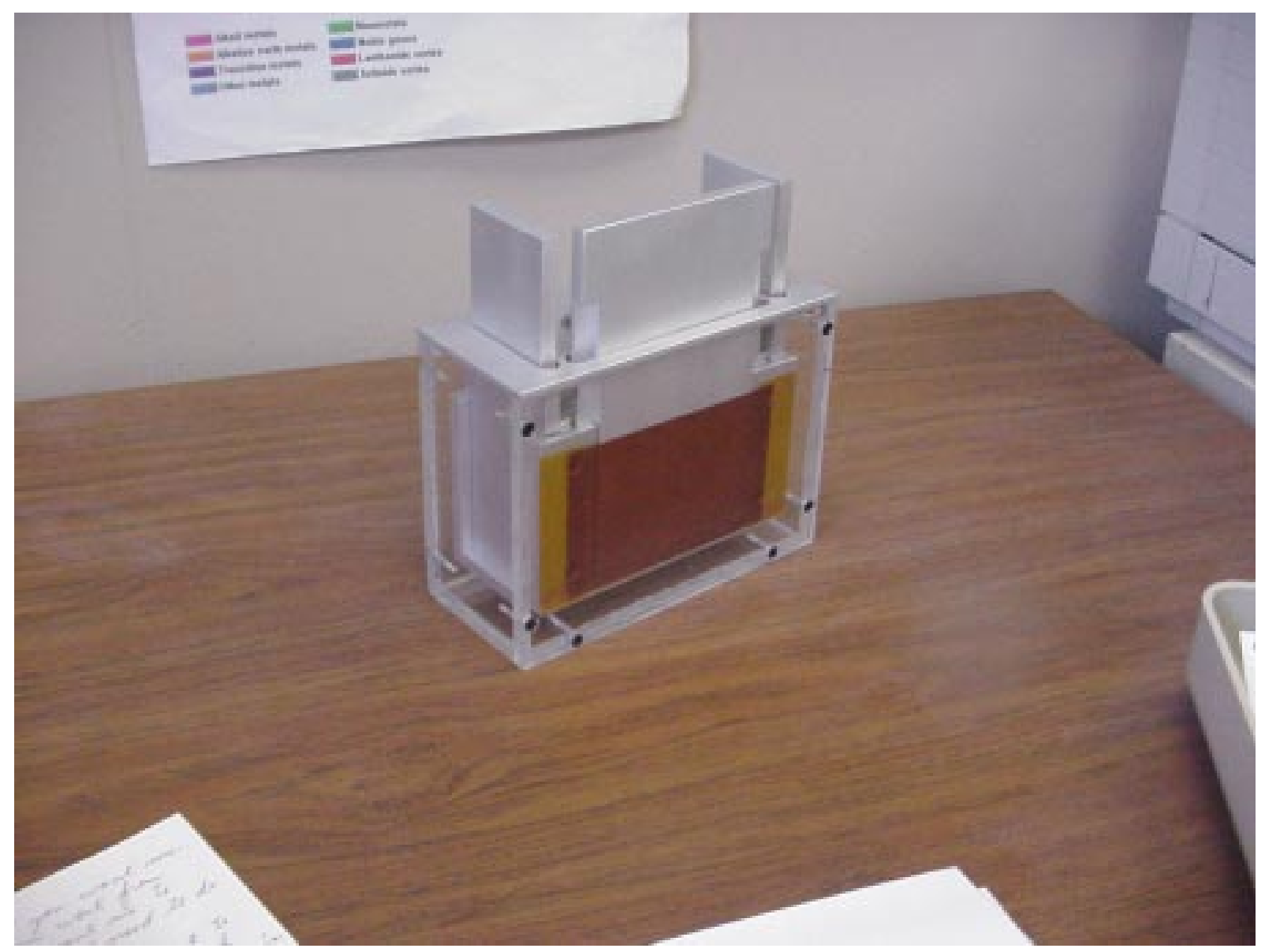

Figure 3-6 Image of the inner portion of the sample box, which shows closed guillotine doors. The inner portion of the box is visible through a plastic rendition of the outer Al metal box. X-ray invisible brown kapton film and tape comprise the primary window in the front of the largest guillotine door.

\subsubsection{XANES and EXAFS Da ta Collection}

\subsubsection{Studies Conducted at the National Synchrotron Light Source}

The XAFS data were collected on beamline X23a2 (Figure 3-8 and Figure 3-9) at the National Synchrotron Light Source (NSLS, Brookhaven National Laboratory, Upton, NY). Uranium-XAFS data were collected at the $\mathrm{U} \mathrm{L}_{3}$-edge $(17166 \mathrm{eV})$ and $\mathrm{Hg}$-XAFS data were collected at the $\mathrm{Hg} \mathrm{L}_{3}$-edge $(12284 \mathrm{eV})$ on the sludge samples. The XAFS data were collected in fluorescence mode using an unfocussed X-ray beam and a fixed-exit $\mathrm{Si}(311)$ monochromator (X23a2). Ion chambers were used to collect incident (Io), transmission (It) and reference (Ir) signals. Simultaneous data collection of a reference (Ir) signal was performed by measuring an yttrium foil (for U). The gas used for data collection in Io was $100 \%$ Ar. 


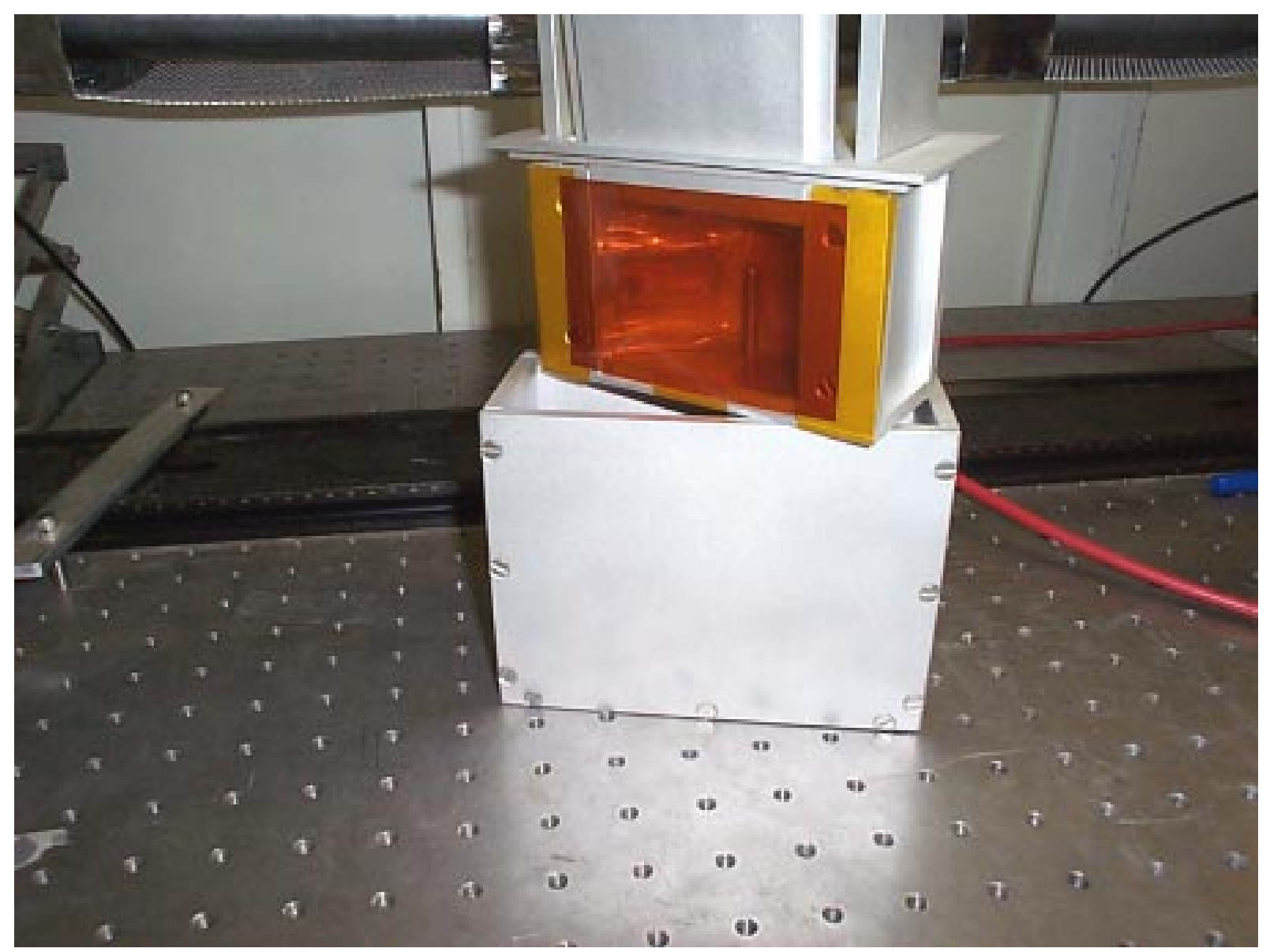

Figure 3-7 View of the Al sample box outside of its primary box with all three of the guillotine doors open.

A 13-element detector was used to collect fluorescence X-rays (If), using an Al metal foil or $\mathrm{SrCO}_{3}$ foil to reduce the background fluorescence counts (shown in Figure 3-9, Figure 3-10, and Figure 3-11). This type of detector is more sensitive than the Lytle detector and requires considerable setup time and technical expertise. The window shown in Figure 3-11 shows the raw X-ray fluorescence signal coming from the Tank 8F sample. The area under the peaks is proportional to the sample concentration. The highest peak is due to Compton scattering as shown with the green arrow. Energy regions of interest are selected with this mass channel analyzer and the final signal from the 13-element detector is then sent to a computer, which stores the collected data.

The monochromator energy was maximized using a piezo stack feedback energy stabilization system, with a settling time of 0.3 seconds per change in monochromatic energy. An X-ray beam size of 2 by $28 \mathrm{~mm}^{2}$ was used. Beamline energy calibration was done using foils of $\mathrm{Pt}\left(\mathrm{L}_{1}\right.$-edge of 13,880 eV), $\mathrm{Zr}$ (K-edge, 17,998 eV), and Mo (K-edge, 20,000 eV). 
WSRC-TR-2001-00428, REV. 0

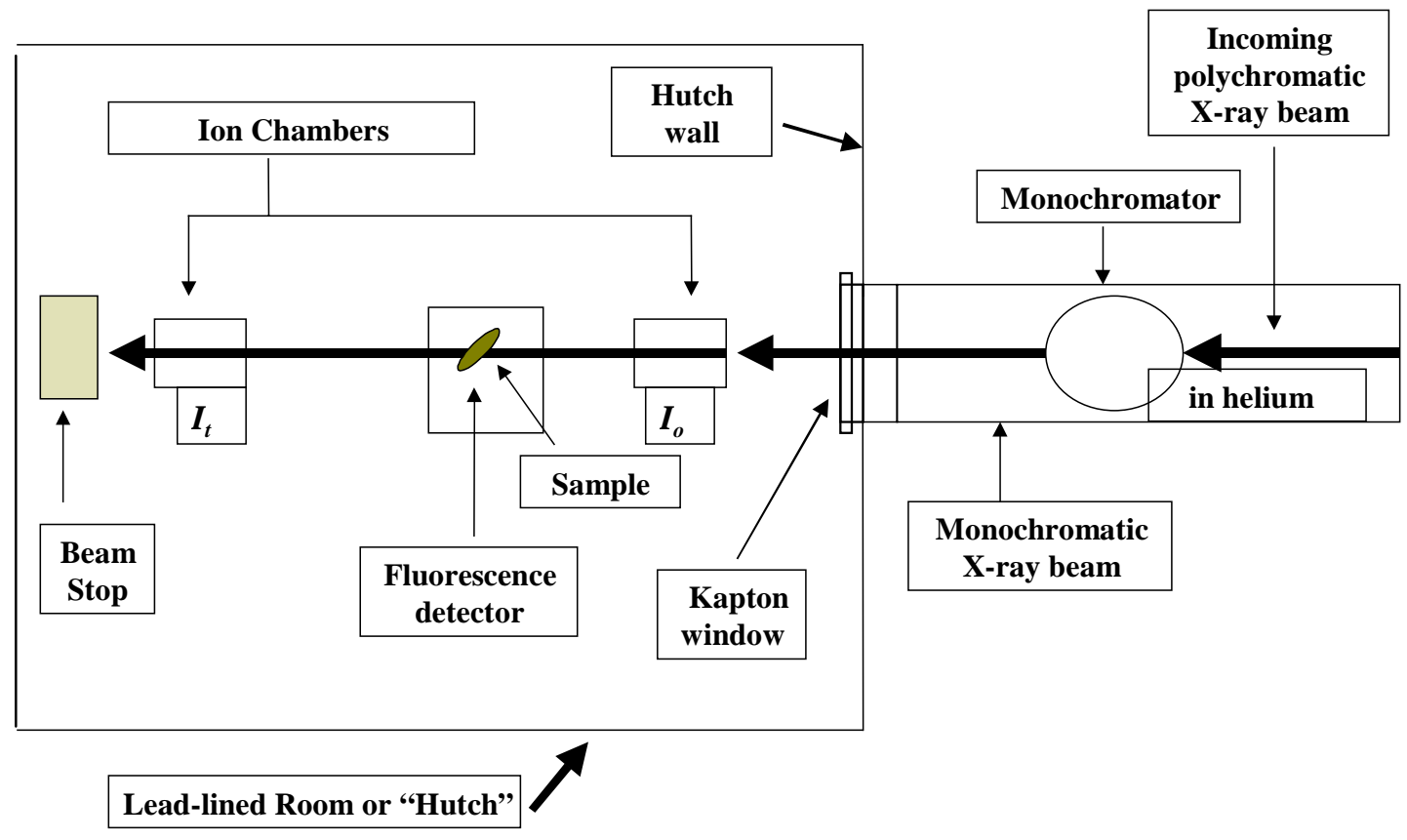

Figure 3-8 Diagram of the downstream portion of the hutch table at NIST beamline X23a2 (not drawn to scale).

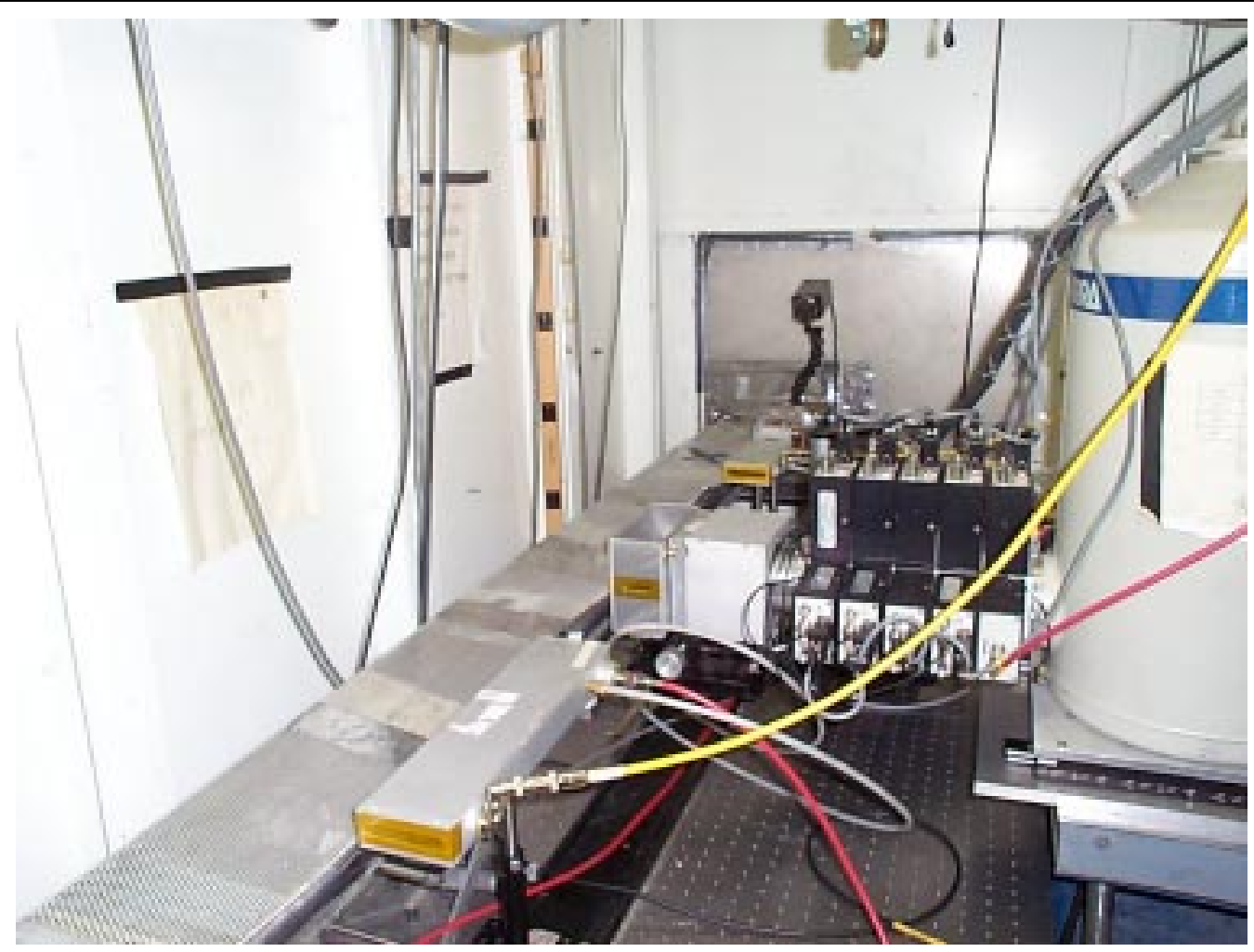

Figure 3-9 Image of the hutch table (looking upstream toward the entrance of the X-ray source) showing the linkage of the 13-element detector to the Lytle Detector box, which is in line with the X-ray beam. 


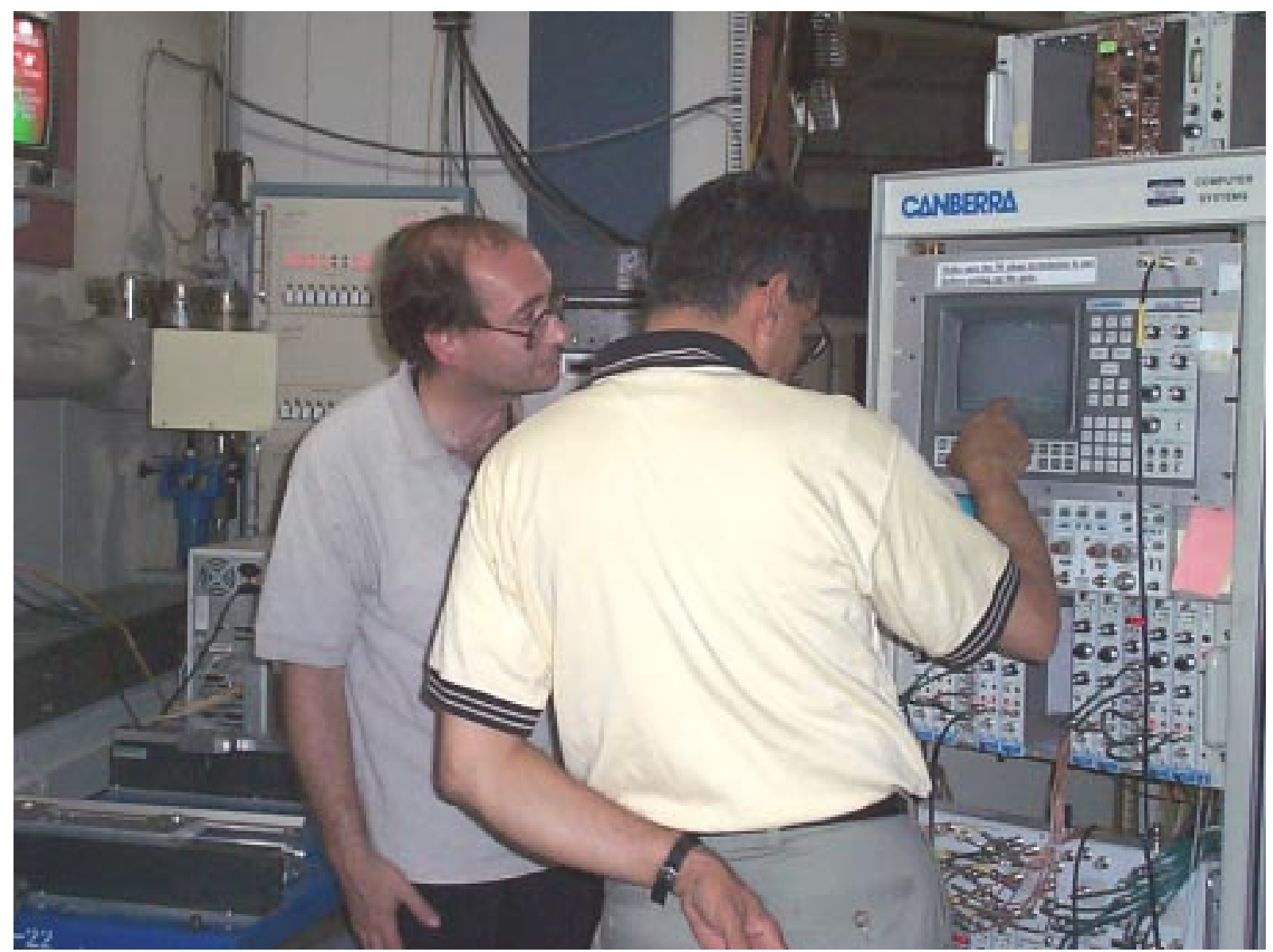

Figure 3-10 Setting up the 13-element detector at the NSLS. The large screen on the detector shows the raw X-ray fluorescence signal coming from the sample.

\subsubsection{EXAFS Data Analyses}

Most of the elements in the 13-element detector were working optimally. However, some elements proved noisy and likely to contribute more noise than usable signal. To identify which detectors performed the best, we developed a program that could ascertain which detectors would contribute a good $\mathrm{S} / \mathrm{N}$ and which detectors if included in the data analyses would detract from the quality of the overall sample signal. Interfacing the detector to the acquisition software was limited to direct data logging of the signal from each detector element in the multi-element detector array. Each element was written to a column in an ascii formatted file. Given the radioactivity of the samples, only limited optimization of detector position was possible. Even under optimal positioning of the detector, a spread of signals was expected since elements are spatially discrete within the detector array.

A computer program was written to calculate the normalized variance in the EXAFS portion of the data for each element in the detector. The elements were ranked according to the best $\mathrm{S} / \mathrm{N}$. Signal-to-noise was ascertained from the edge step normalized variance in the 
EXAFS portion of the data. Elements were then sequentially co-added according to their S/N ranking, i.e., Rank 1, Rank1+Rank2, Rank1+Rank2+Rank3... Each summation was exported to an ascii file readable by the EXAFS analysis software package, WinXAS. Each output file from this procedure was imported into WinXAS, converted into chi data and visually compared. The summation of elements that exhibited the smallest peak-to-peak noise in $\mathrm{k}^{2}$-weighted $k$-space was selected as the best $\mathrm{S} / \mathrm{N}$ combination of elements from the array. Out of the 13 elements in the detector array, summation of the best 7 elements gave the lowest peak-to-peak noise once the data was converted into $k$-space. The file output for the summation of the top 7 ranked elements were then used for each scan on a given sample and analysis proceeded in the standard manner.

The background contribution to the EXAFS spectra was removed using an algorithm (AUTOBK) developed by Newville et al. (1993), which minimizes R-space values in low $k$ space. Each chi data set was read into the WINXAS analysis package. ${ }^{5,6}$ Replicate scans were co-added to improve $\mathrm{S} / \mathrm{N}$. The $\mathrm{U}$-XAFS spectra were collected to $850 \mathrm{eV}$ beyond the $\mathrm{U}$ $\mathrm{L}_{3}$-edge and the EXAFS data were analyzed from 2 to $14 \AA^{-1}$. The Hg-XAFS spectra were analyzed from 2 to $9 \AA^{-1}$. The chi data were $k^{2}$-weighted and Fourier-transformed to yield Rspace data. ${ }^{7}$ Simulated EXAFS spectra were also generated based on the documented crystallographic properties for $\mathrm{U}$ and $\mathrm{Hg}$ using ab initio based theory, which involved FEFF 7.2 a program created by researchers at the Univ. of Washington. $8,9,10,11,12,13$ Model fits for $\mathrm{U}$ and $\mathrm{Hg}$ were performed in $\mathrm{R}$-space. 
WSRC-TR-2001-00428, REV. 0

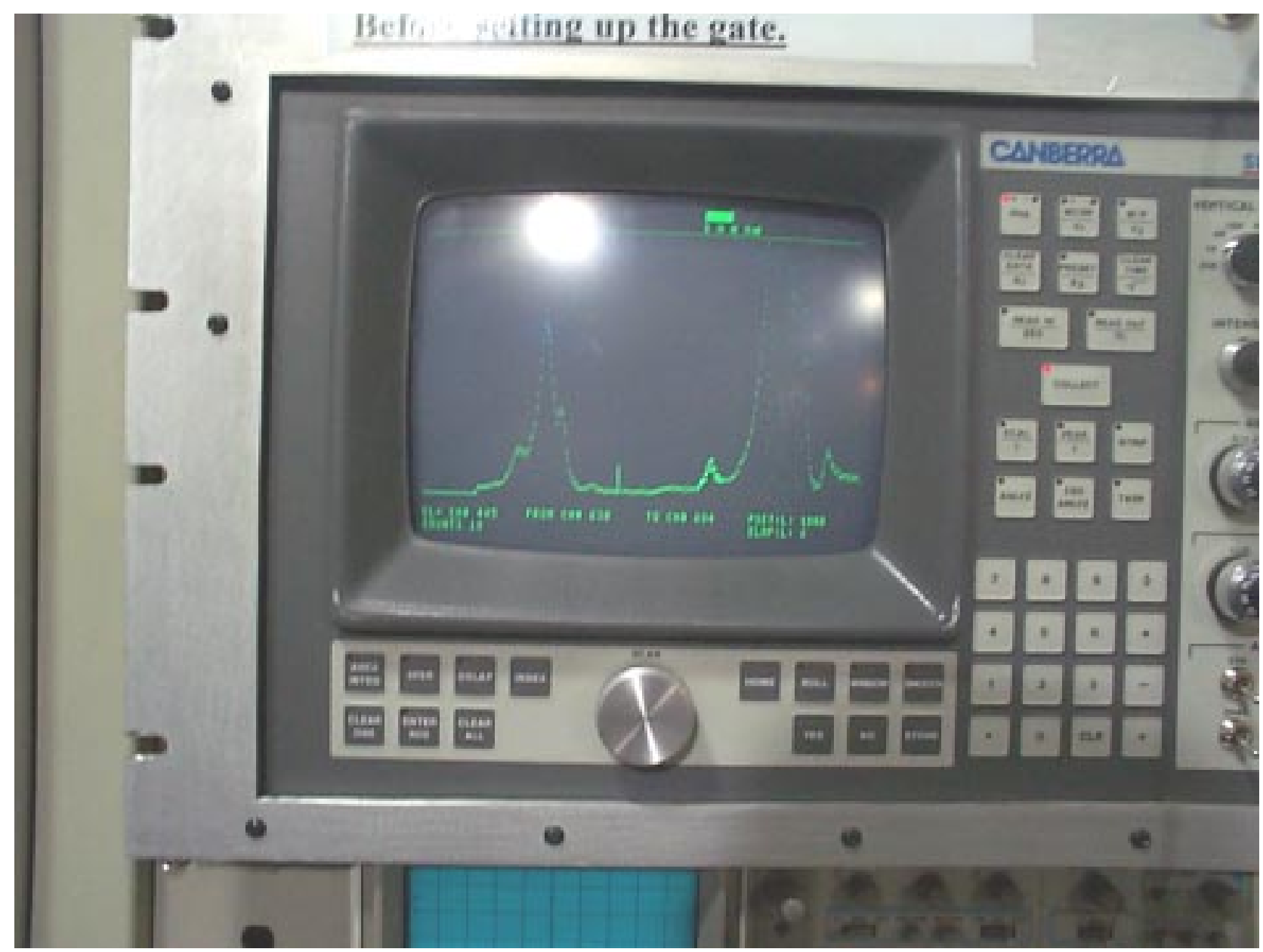

Figure 3-11 The main window containing the output from the mass channel analyzer for the 13-element detector. 


\subsection{RESULTS}

\subsubsection{Background on the Cha racterization of U Solids with XAFS}

The XAFS techniques have been applied to the study of U(VI) on a variety of sorbents, such as Fe oxides, silicates and sulfides ${ }^{14,15,16,17,18, ~ 19, ~ 20, ~ 21, ~} 22$ in HLW simulant solutions and within mineral oxides, calcite, oxyhydroxides and gels. ${ }^{23,24,25,26,27}$ Most of these studies have an environmental focus because they were performed with naturallyoccurring minerals and U-containing minerals under conditions relevant to the geologic surface and subsurface environments.

\subsection{EXAFS Analyses}

In simple terms, chi data (the plot of the wavevector in reciprocal space) show the oscillation patterns (both constructive and destructive interference patterns) of the atoms in the neighbor environment of the element of interest. The chi data represent part of the photoelectron wave that can be defined by the EXAFS equation. ${ }^{1,2,28}$ The EXAFS equation is shown in a highly simplified form below (see list of definitions for explanation of equation terms).

$$
\operatorname{Chi}(\mathrm{k})=\frac{\mathrm{F}(\mathrm{k}) * \mathrm{~N} * \mathrm{~S}}{\mathrm{k} * \mathrm{R}^{2}} S_{0}^{2} e^{\left(-2 * \mathrm{k}^{3} \sigma^{2}\right)} \sin [2 * \mathrm{k} * \mathrm{R}+\delta(\mathrm{K})]
$$

\subsubsection{Raw Energy Scan and Chi Data for the U in the Tank 8F Sludge}

The raw EXAFS data for $\mathrm{U}$ in the Tank 8F sludge is shown in Figure 4-1. Although we did not perform XANES analyses, the presence of a shoulder feature on the high-energy side of the white-line peak absorption edge indicates the sample is probably rich in hexavalent $\mathrm{U}$ as shown in Figure 4-1. The $k^{2}$-weighted chi spectra for U in the HLW Tank 8F sludge sample is shown in Figure 4-2. The useable range extends to about $12 \AA^{-1}$.

\subsubsection{Normalized Energy Scan and Chi Data for $\mathrm{Hg}$ in the Tank 11H Sludge}

Fluorescence data was collected on HLW sludge sample 11H using the multi-element detector. Data was collected out to $340 \mathrm{eV}$ above the absorption edge (Figure 4-3 ). This scan provided EXAFS data of reasonable S/N but low resolution. The extracted $k^{2}$-weighted chi data are shown in Figure 4-4. The limited range in energy scan translates to a chi range of $9 \AA^{-1}$. The data was of sufficient quality to conduct a first shell analysis. 
WSRC-TR-2001-00428, REV. 0

Sample U8F, U EXAFS X23A2, Fluorescence

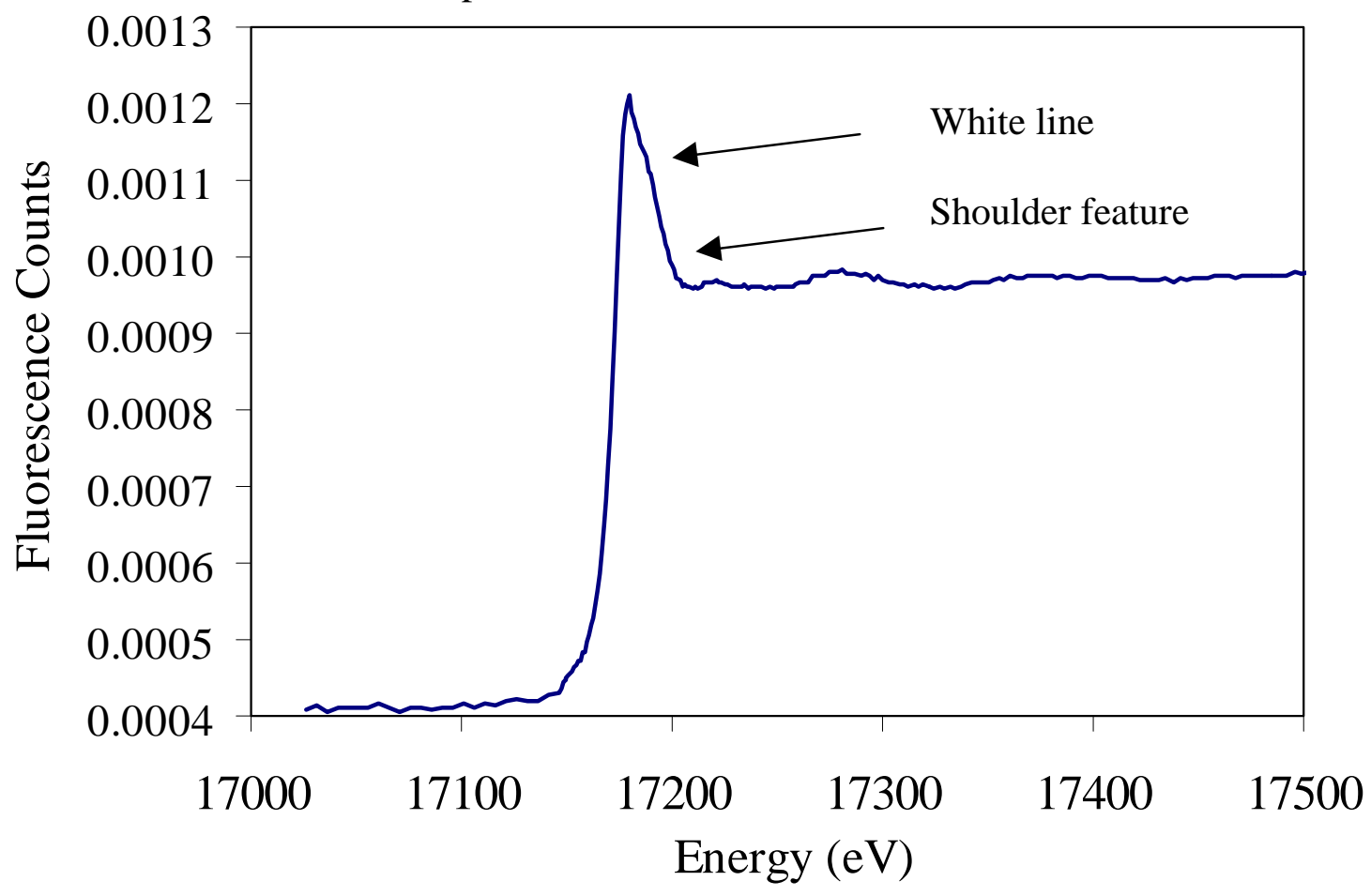

Figure 4-1 Raw U EXAFS spectra for $\mathrm{U}$ in the HLW Tank 8F sludge.

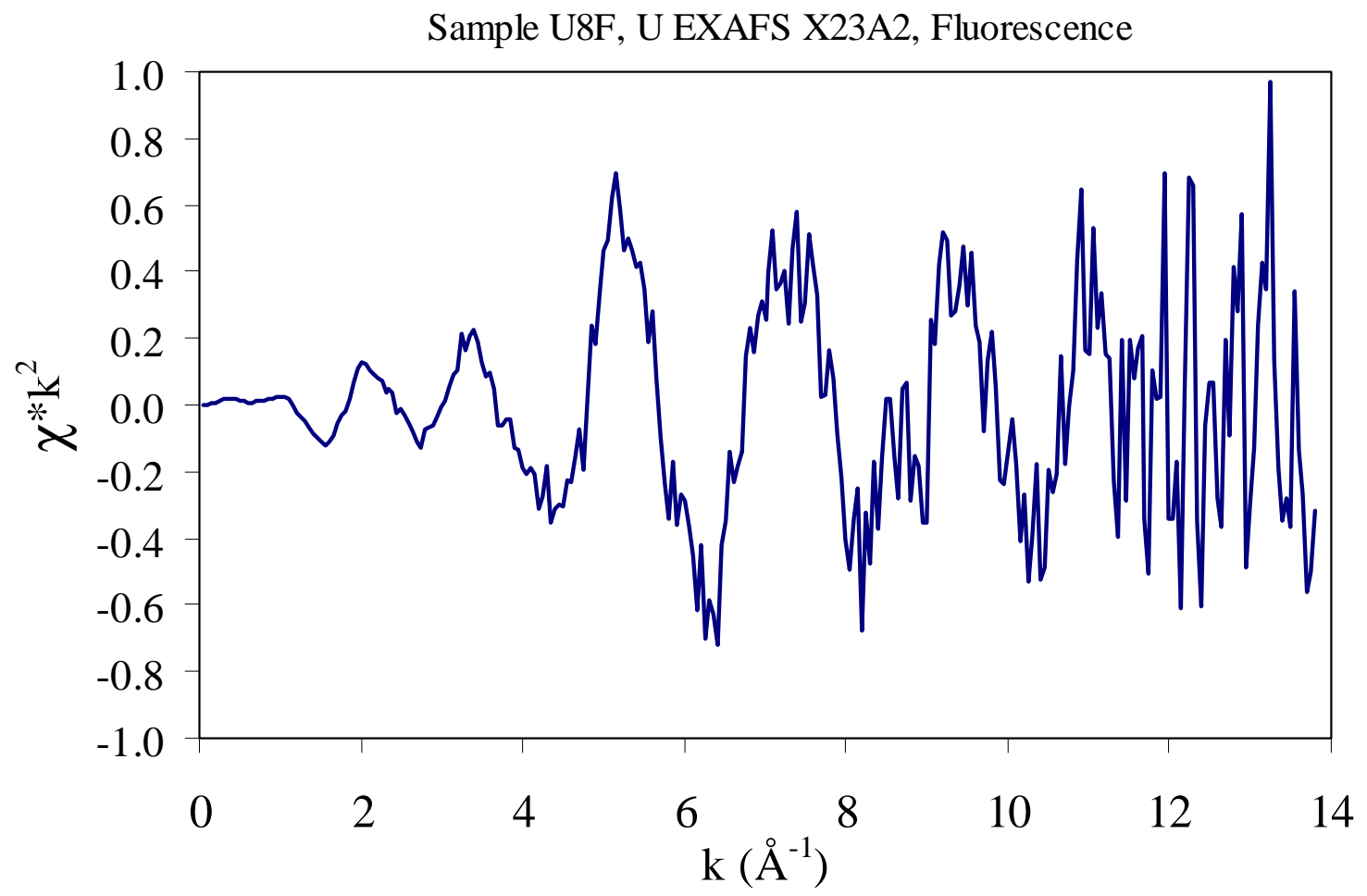

Figure 4-2 The $k^{2}$-weighted chi data (the plot of the wavevector in reciprocal space) for $\mathrm{U}$ in the Tank $8 \mathrm{~F}$ sludge. 
WSRC-TR-2001-00428, REV. 0

Sample Hg11H, Hg EXAFS X23A2

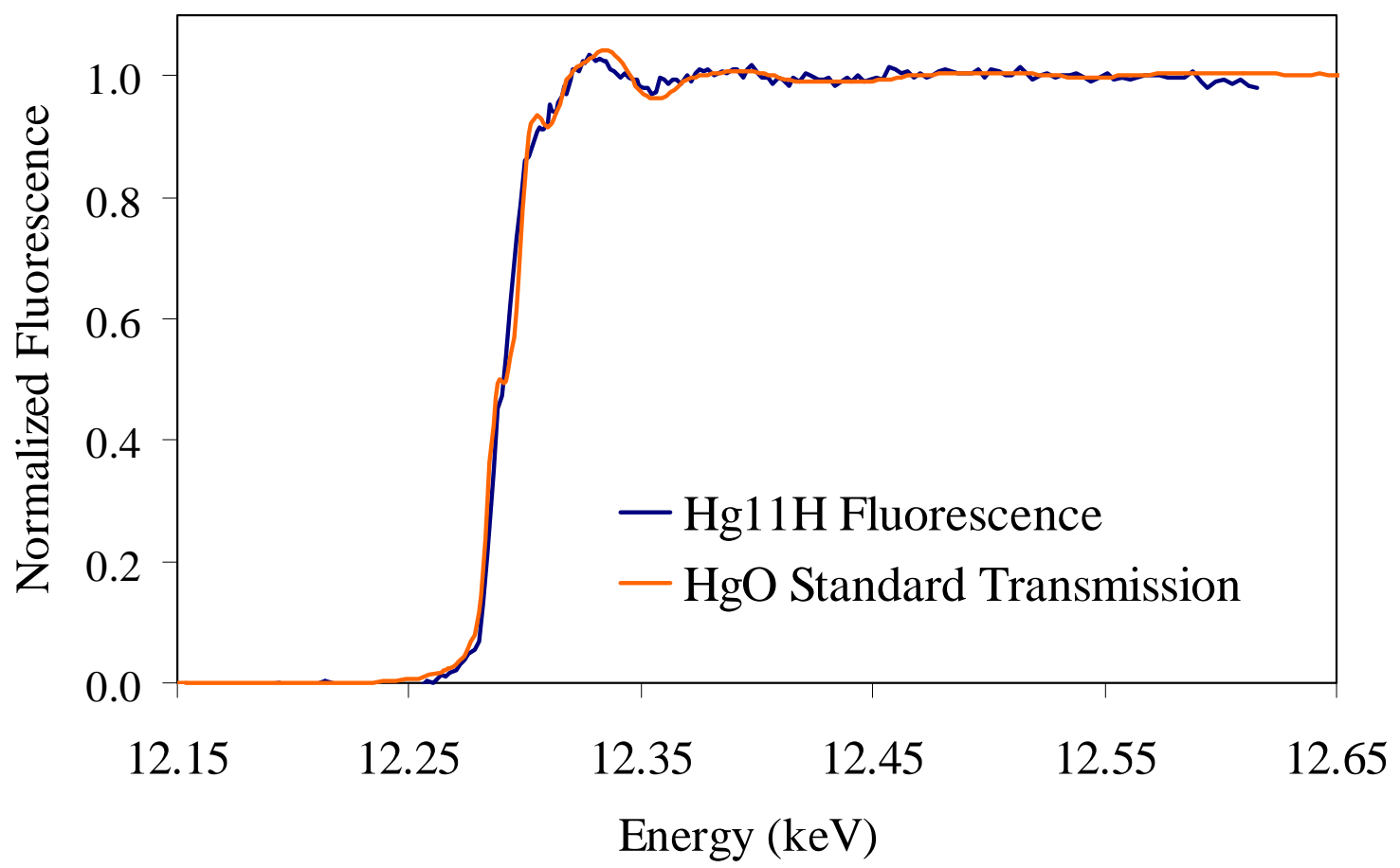

Figure 4-3 Normalized $\mathrm{Hg}$-XAFS spectra for $\mathrm{Hg}$ in the HLW Tank $11 \mathrm{H}$ sludge. The $\mathrm{HgO}$ spectra are from Duff et al. (2000). ${ }^{29}$

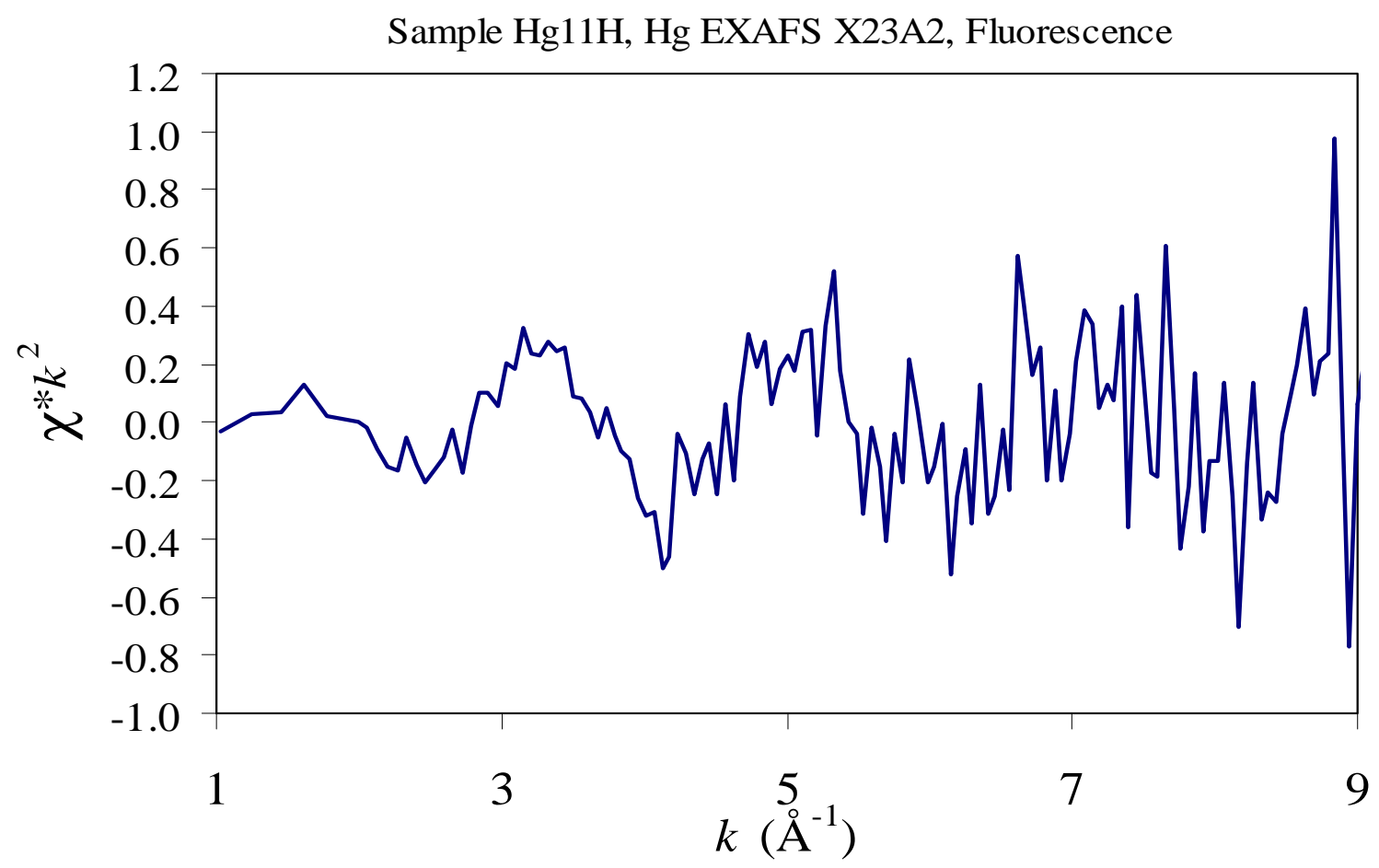

Figure 4-4 The $k^{2}$-weighted chi data for $\mathrm{Hg}$ in the Tank $11 \mathrm{H}$ sludge. 
WSRC-TR-2001-00428, REV. 0

\subsubsection{Fourier-Transformed Data}

\subsubsection{Fourier-Transformed and Model Fit Data for $U$ in the Tank 8F Sludge}

Our chi data for $U$ were of sufficient quality to conduct a multi-shell analysis out to 4 $\AA$ in R space. The Fourier transform of $k^{2}$-weighted chi data is shown in Figure 4-5. Close inspection shows that the peaks of the imaginary and real components of the transform do not coincide with the first major peak centered at $1.57 \AA$ (uncorrected for phase shift). This occurrence is indicative of overlapping shells. When the first peak in the transform was backtransformed (Fourier filtered), the presence of multiple signals was apparent from the presence of a beat pattern (data not shown). The data were therefore fit in $\mathrm{R}$ space because fitting in chi space is best done when there are not a lot of overlapping shells. Uranyl axial O atoms (Oax) with a radial distance at $1.8 \AA$ from the U usually exhibit peaks at $\sim 1.3 \AA$ in the Fourier transform. Our first attempt to fit the data was to add $\sim 0.5 \AA$ to the peaks in the Fourier transform spectra and fit for $\mathrm{O}$ atoms at 2.1 and $2.4 \AA$. This attempt did not yield good fits. Our next attempt included a third sub-shell consisting of another Oeq. The fit results for $3 \mathrm{O}$ subshells are shown in Figure 4-5. Designation of the atoms that contribute to the prominent peaks in the transform were made by fitting the EXAFS data in R and k space in conjunction with model simulations in Rotate_Atoms ${ }^{\mathcal{O}}$. Table 4-1 enumerates the fit results. The results show two Oax at $1.87 \AA$, which is evidence that the $\mathrm{U}$ is predominately $\mathrm{U}(\mathrm{VI})$. There are two additional O subshells at $2.22 \AA$ and $2.37 \AA$, which are consistent with the spread of Oeq often observed for $\mathrm{UO}_{2}{ }^{2+}$ solid and solution species. ${ }^{24,23}$

The next three peaks in the transformed data (Figure 4-6) are located at $2.57 \AA, 2.87$ $\AA$ and $3.8 \AA$ (uncorrected for phase shift). It was not necessary to fit the peak at $2.57 \AA$ as this was accounted for as an artifact of overlaps with other shells. The peaks at $2.87 \AA$ and 3.8 $\AA$ are representative of heavy mass atoms. Uranium and $\mathrm{Hg}$ are the most common heavy element atoms in the $8 \mathrm{~F}$ sample. Uranium gave a much better fit over $\mathrm{Hg}$ for the identity of the atoms in both shells. The distance of the further $U$ shell (at $3.86 \AA$ ) is consistent with polymeric U(VI) species. The closer uranium shell at $3.02 \AA$ is surprising to us because the distance is quite short (Figure 4-6). This is too close to be a U-O-U multiple-scattering resonance (MSR) interaction. Inspection of U-U metal interactions reveals that gammauranium metal has U-U bond distances of 3.01 $\AA$. The cubic structure of gamma U metal indicates that the $\mathrm{CN}$ should be 8 but our fits suggest a U-U CN of 0.48 . We can interpret this reduction in coordination number to arise from multiple phases of $U$ present in the sludge. Indeed this must be true since we have concluded the presence of U(VI) species. The reduction of $\mathrm{CN}$ from 8 to 0.48 suggests that only $6 \%$ of the total $\mathrm{U}$ exists as gamma $\mathrm{U}$ metal. This percentage is within the error of $\mathrm{CN}$ determination for the U(VI) and explains why the $\mathrm{CN}$ values were consistent for the uranyl species. A small peak at $3.2 \AA$ (uncorrected for phase shift) was not modeled in our fits. This peak is at the appropriate distance for the next $\mathrm{U}$ metal atom in the gamma $\mathrm{U}$ metal structure. However, we were unable to perform fits to model this U-U interaction due to our limited degrees of freedom.

Page 24 of 33 


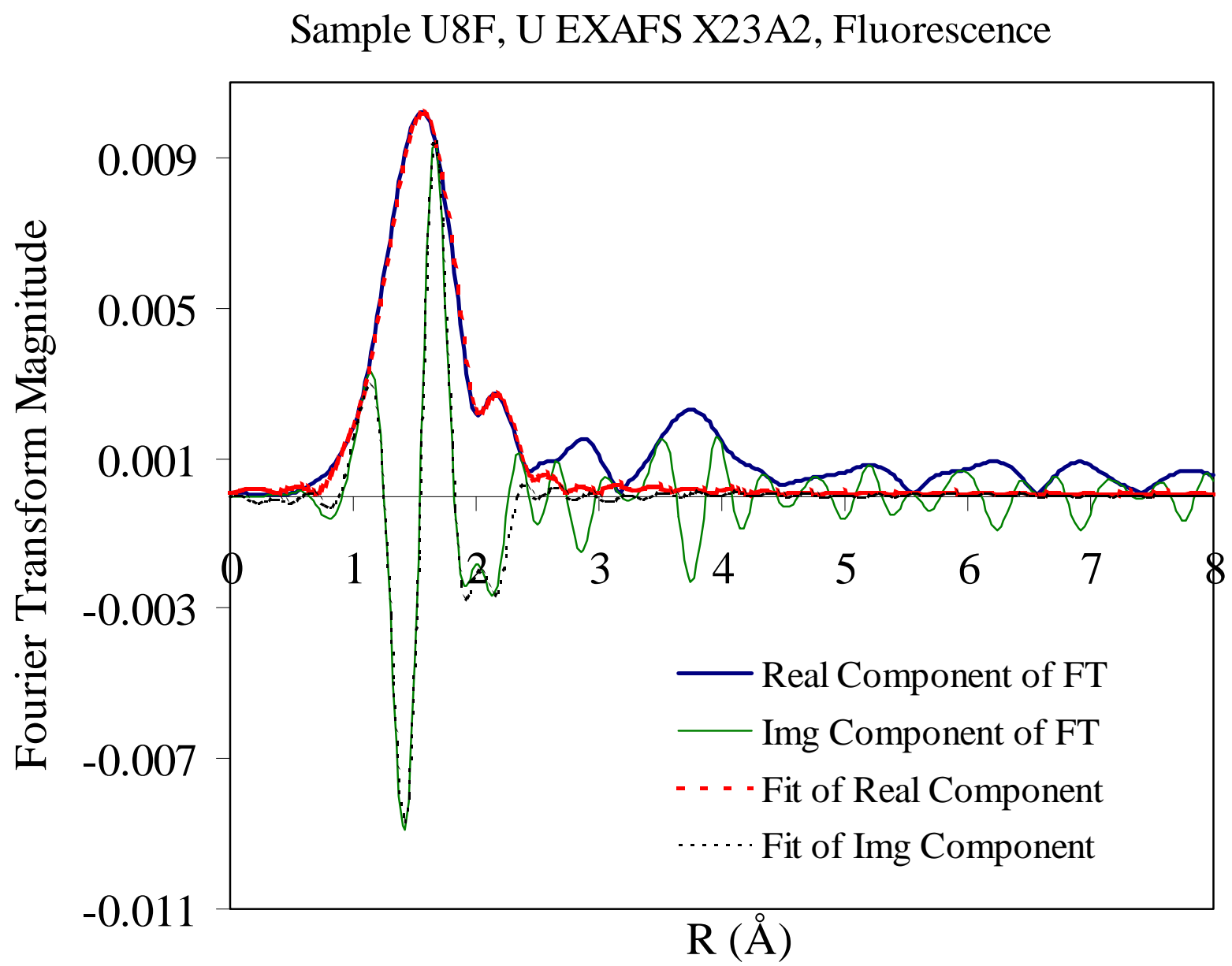

Figure 4-5 FT RDF and first shell model fit data for U in the Tank 8F sludge- uncorrected for phase shift. 
Table 4-1 Fit results for the U in the HLW Tank 8F sludge sample (performed in R space). The magnitude of the Debye-Waller Factor [represented as $\left.\sigma^{2}[\AA]^{2}\right]$ indicates the variation of the bond length determination (or spread but not error). It also provides information on goodness of fit—for example, a negative value would indicate a poor fit.

\begin{tabular}{|c|c|c|c|c|}
\hline Sample & Interaction & $\mathbf{C N}$ & Distance $\mathbf{R}[\AA]$ & $\sigma^{2}[\AA]^{2}$ \\
\hline \multirow[t]{3}{*}{ U8F } & U-Oax & 2.12 & 1.87 & 0.005 \\
\hline & U-Oeq & 5.52 & 2.22 & 0.005 \\
\hline & U-Oeq & 5.24 & 2.39 & 0.007 \\
\hline \multirow[t]{5}{*}{$\mathrm{U} 8 \mathrm{~F}$} & U-Oax & 2.12 & 1.87 & 0.004 \\
\hline & U-Oeq & 5.52 & 2.22 & 0.004 \\
\hline & U-Oeq & 5.24 & 2.39 & 0.006 \\
\hline & U-U & 0.49 & 3.03 & 0.002 \\
\hline & U-U & 1.48 & 3.86 & 0.002 \\
\hline
\end{tabular}

Sample U8F, U EXAFS X23A2, Fluorescence

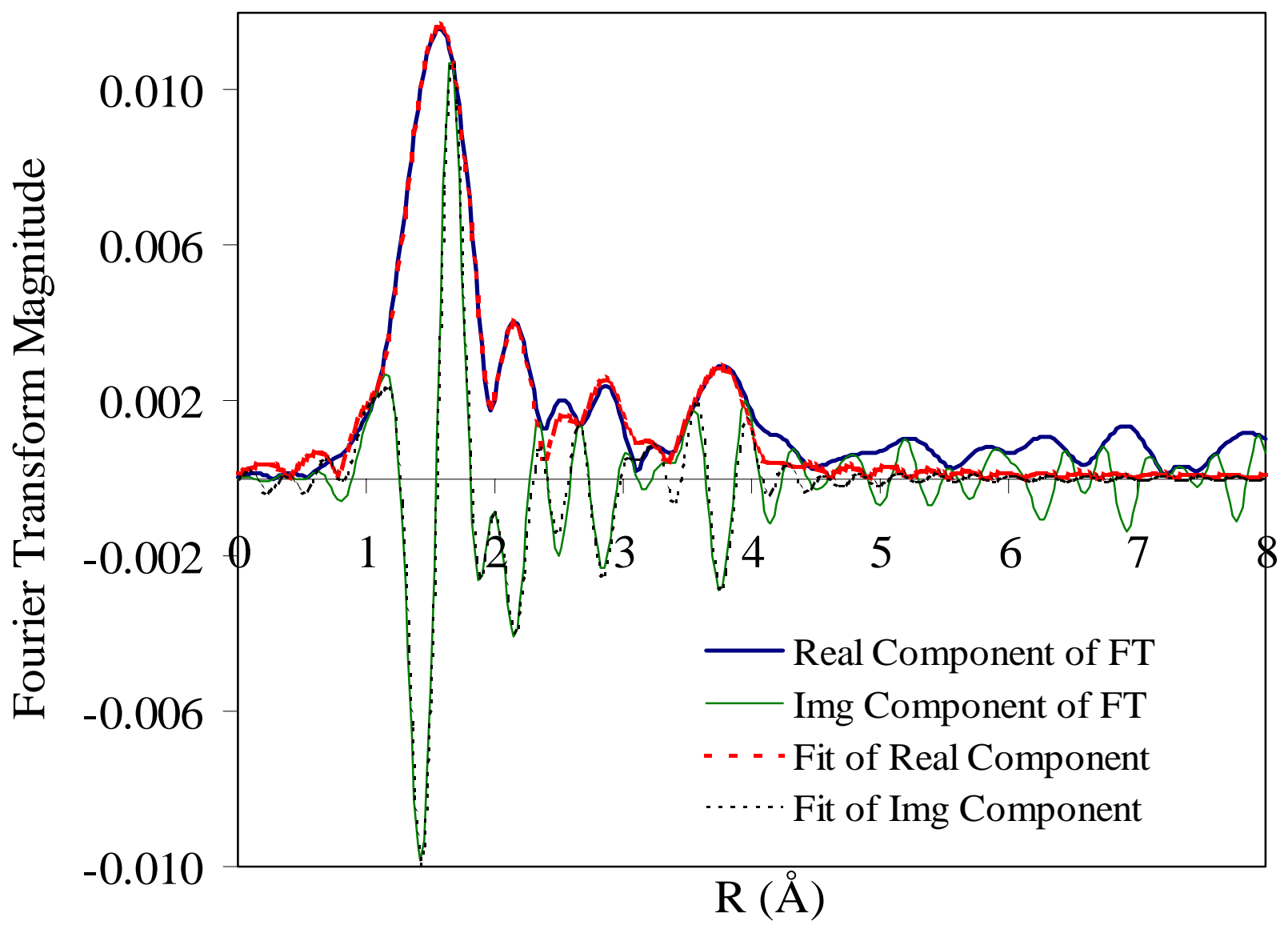

Figure 4-6 FT data and multiple shell modeling results for the $U$ in the HLW sludge Tank 8F sample-uncorrected for phase shift.

Page 26 of 33 
Sample U8F, U EXAFS X23A2, Fluorescence

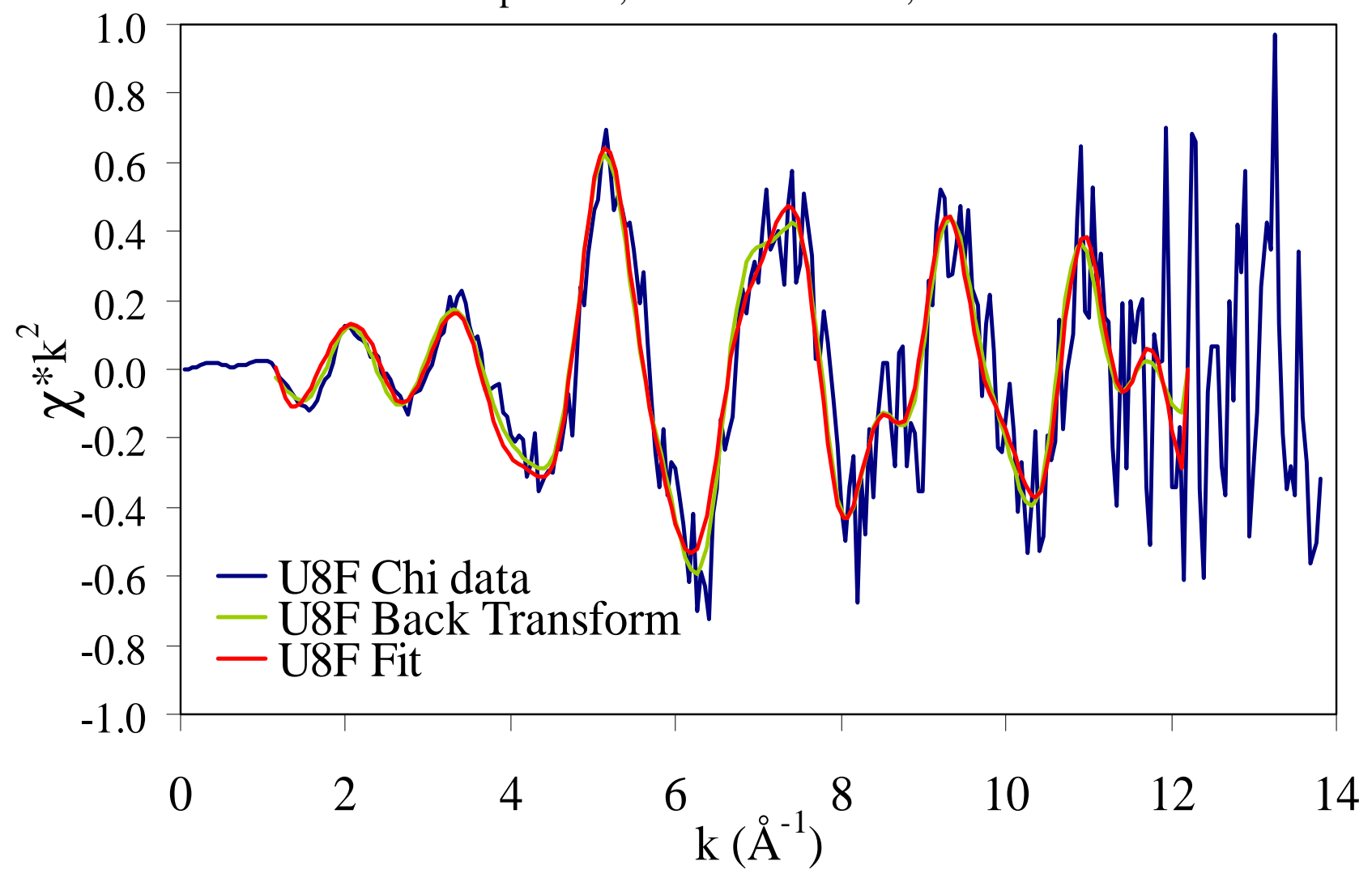

Figure 4-7 Fourier-filtered data for $\mathrm{U}$ in the Tank $8 \mathrm{~F}$ sludge. The unfiltered chi data for $\mathrm{U}$ are shown with the back transformed data from the multishell fits in R space.

\subsubsection{Model Fits in Chi Space for the $U$ in the Tank 8F Sludge Sample}

The FT data and model fit data were Fourier filtered (or back-transformed) so that the EXAFS data could be compared (Figure 4-7). The fits that were generated in R-space compared well in k-space for Sample 8F. Collectively, we conclude that the bulk of the U present in sludge sample $8 \mathrm{~F}$ is of the $\mathrm{U}(\mathrm{VI})$ oxidation state with some polymerization indicative of colloidal uranium(VI) oxyhydroxide species. In addition, 5\% of the $\mathrm{U}$ present in the sludge is present as zero valent $\mathrm{U}$ metal. Depleted $\mathrm{U}$ metal was used to produce Pu in Farea. The U metal we detect from are EXAFS analyses is possibly the leftover (undissolved) waste product from $\mathrm{Pu}$ recovery or it may be waste leftover (i.e., metal filings) after the $\mathrm{Pu}$ metal was extruded.

\subsubsection{Mercury Fourier Transform and Model Fit Data for Hg in the Tank 11H Sludge Sample}

The Fourier transform of $k^{2}$-weighted chi data is shown in Figure 4-8. The first peak at $1.32 \AA$ (uncorrected for phase shift) was back transformed and fit to oxygen. The results of the fit are listed in Table 4-2. The second peak at $2.37 \AA$ (uncorrected for phase shift) was 
also back-transformed and fit to $\mathrm{O}$ (Figure 4-9). These two shells for $\mathrm{O}$ atoms with distances of $2.06 \AA$ and $2.75 \AA$ are in close agreement to the mineral montroydite $(\mathrm{HgO})$ which has $\mathrm{O}$ atom shells at $2.03 \AA$ and $2.8 \AA .{ }^{30}$ We can conclude that a $\mathrm{Hg}$ (II) oxide is present in the sludge waste and that implies an oxidation state of $+\mathrm{II}$ for $\mathrm{Hg}$. However, the $\mathrm{CN}$ values resulting from these fits are extremely small (1.26 and 1.07 for the first and second $\mathrm{O}$ atom shells respectively as in Table 4-2. The $\mathrm{Hg}$ in montroydite is 6-fold coordinate with six first shell $\mathrm{O}$ atoms (two $\mathrm{O}$ atoms each at three distances of $2.03 \AA$, at $2.80 \AA$ and at $2.9 \AA$ ).

A diminution of the EXAFS oscillations (which corresponds to the smaller $\mathrm{CN}$ values is clearly seen in Figure 4-4 in which the step-normalized absorption scan for $\mathrm{Hg}$ in sludge sample $11 \mathrm{H}$ is overlaid on an $\mathrm{HgO}$ reference standard. This suggests that mercury has multiple chemical environments that results in an overall destructive interference to the magnitude of the EXAFS oscillations. However, we observe no evidence in the data for significant quantities of $\mathrm{Hg}(0)$ metal since the magnitude of oscillations from $\mathrm{Hg}-\mathrm{Hg}$ interactions would be far greater than that for $\mathrm{Hg}-\mathrm{O}$ interactions.

Sample Hg11H, Hg EXAFS X23A2, Fluorescence

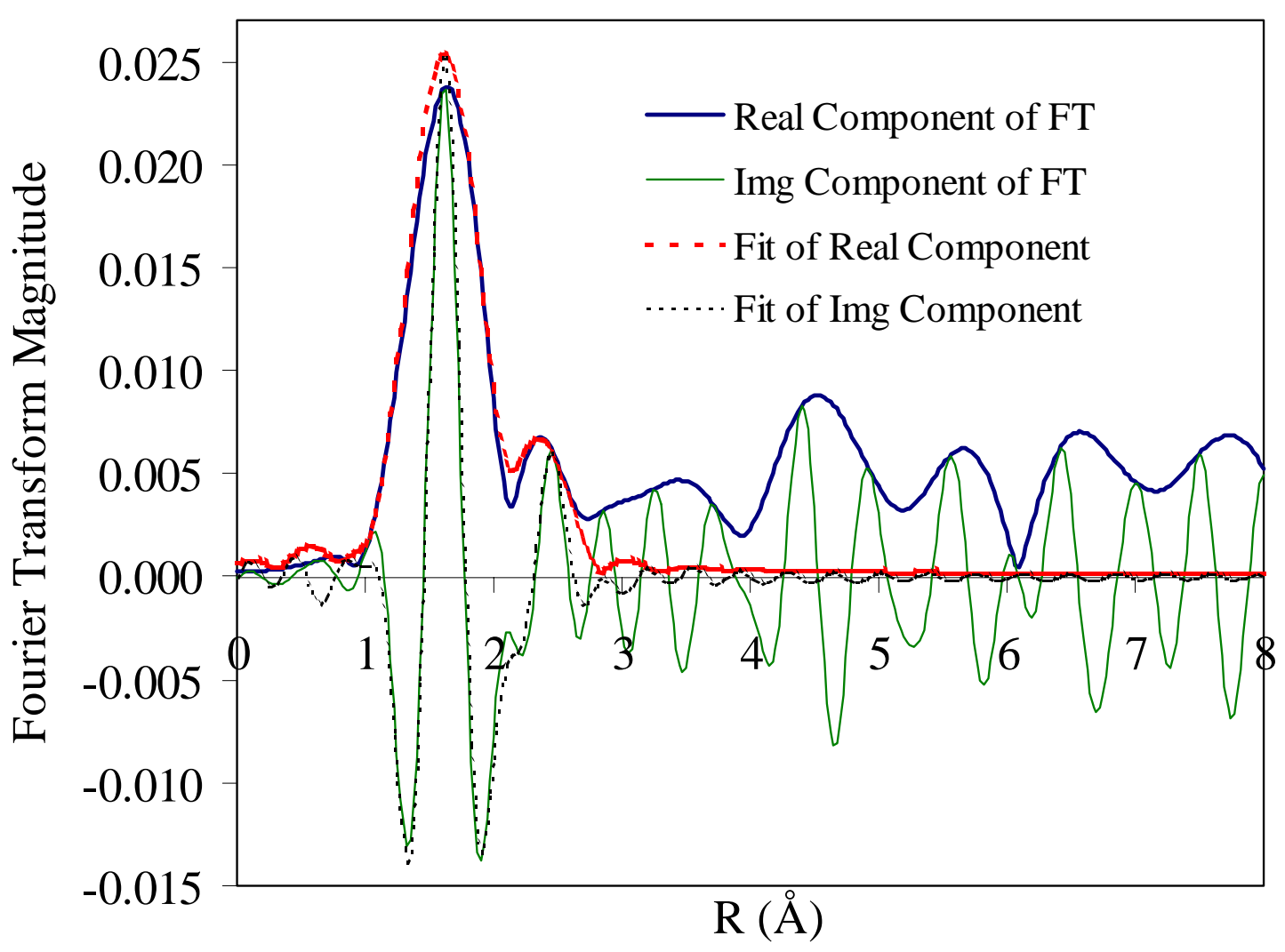

Figure 4-8 FT EXAFS data and model fit data for $\mathrm{Hg}$ in the Tank $11 \mathrm{H}$ sludge sampleuncorrected for phase shift. 
Table 4-2 Fit results for the $\mathrm{Hg}$ in the HLW Sludge Tank $11 \mathrm{H}$ sample (performed in R space). The magnitude of the Debye-Waller Factor [represented as $\left.\sigma^{2}[\AA]^{2}\right]$ indicates the variation of the bond length determination (or spread but not error). It also provides information on goodness of fit-for example, a negative value would indicate a poor fit.

\begin{tabular}{|c|c|c|c|c|}
\hline Sample & Interaction & $\mathbf{C N}$ & Distance R[̊̊] & $\sigma^{2}\left[\AA \mathbf{\AA}^{2}\right.$ \\
\hline $\mathrm{Hg} 11 \mathrm{H}$ & $\mathrm{Hg}-\mathrm{O}$ & 1.26 & 2.06 & 0.001000 \\
& $\mathrm{Hg}-\mathrm{O}$ & 1.07 & 2.75 & 0.007793 \\
\hline
\end{tabular}

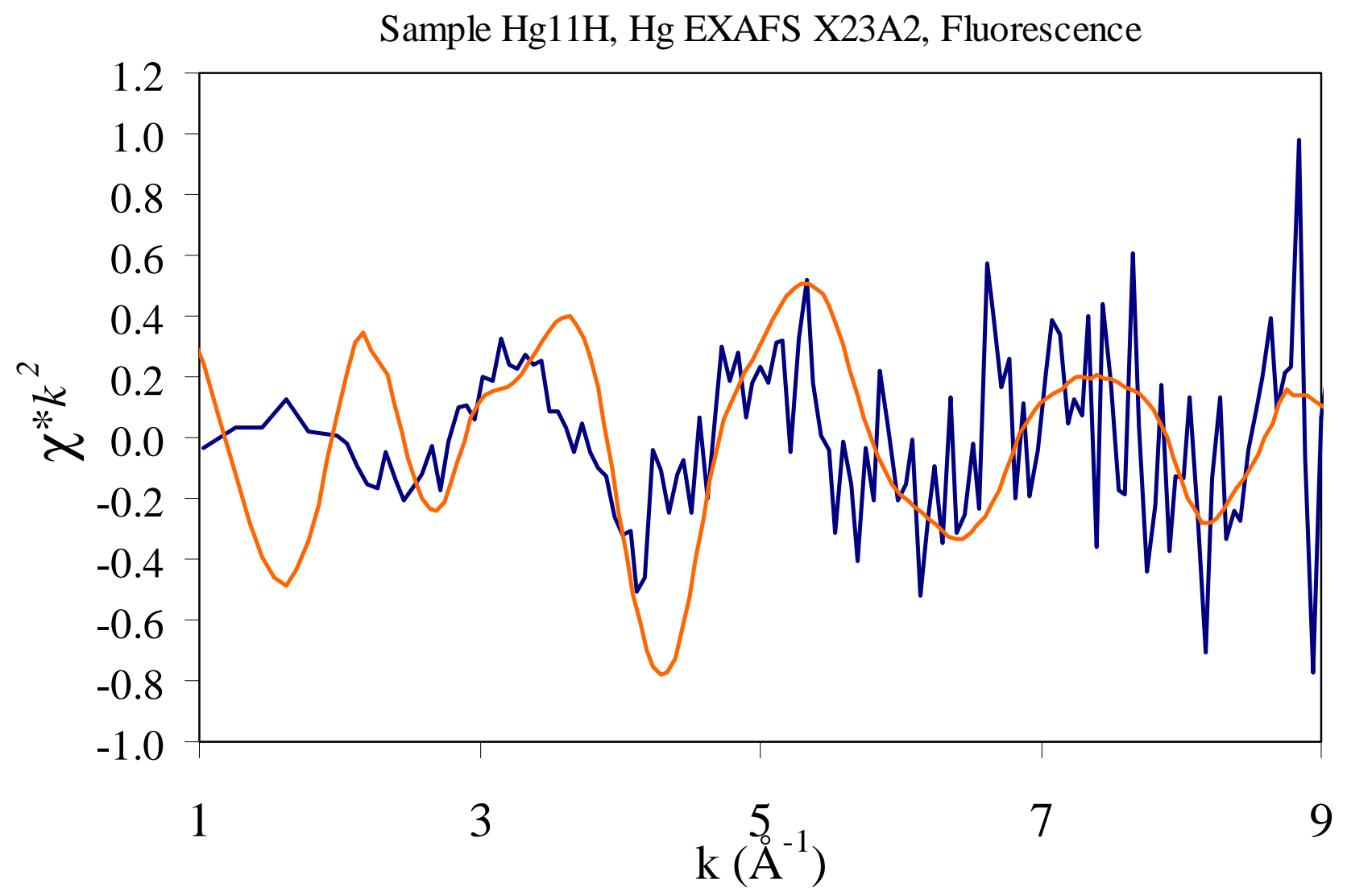

Figure 4-9 Fourier-filtered data for $\mathrm{Hg}$ in the Tank $11 \mathrm{H}$ sludge. The unfiltered chi data for $\mathrm{Hg}$ are shown with the back transformed data from the first shell fits in R space. Fits for the $\mathrm{Hg}$ were not of the same quality as those for the $\mathrm{U}$ in Tank $8 \mathrm{~F}$ sludge. 
WSRC-TR-2001-00428, REV. 0

\subsection{CONCLUSIONS}

Our XAFS studies with these complex waste forms indicate the average U speciation in the SRS HLW tank 8F sludge was predominantly a hexavalent $U$ hydrous oxide form. Some metallic $U$ in the form of gamma- $U$ metal also exists and some of the $U$ is polymeric ( $U$ is present in the second coordination shell). The Hg in the SRS HLW tank 11H sludge sample was an oxidized $\mathrm{Hg}$ (II) form that has first shell $\mathrm{O}$ bonding. This form of $\mathrm{Hg}$ could be a $\mathrm{Hg}$ (II)-nitrate salt, $\mathrm{Hg}$ (II) oxides, a combination thereof or some related O-rich compounds.

Our results have positive impacts to several areas associated with HLW tanks at DOE sites. The information on U provides support to criticality assessments. For example, if dissolution (sluicing) of these materials is attempted, not all of the $\mathrm{U}$ will be readily soluble. Our results also indicate that although $U$ is present in a metallic form, it probably consists of depleted $U$ and is less likely to be a criticality concern than enriched U metal. Depleted U forms are currently used to reduce criticality risks at the SRS.

Although substantial undetected tank rupture and leakage is not a likely event particularly at the SRS, HLW tank rupture and considerable leakage of U, other radionuclides and toxic heavy metals into the groundwater and Columbia River has been extensively observed at the Hanford, WA DOE site. HLW tank source term identification is valuable to predicting contaminant mobility in the subsurface. Should the Tank 8F leak and enter the subsurface environment, our U-XAFS results identify potential U solid phase source terms. The same is the case for our Hg data. To our knowledge, little is known on the speciation of metals in the tanks other than what information has been gained from X-ray diffraction, Raman and FT-IR (Infrared) spectroscopic characterization. X-ray diffraction methods require considerable quantities of crystalline forms of metal solids. Raman and FT-IR methods require spectroscopically active forms of the metals of interest. These methods cannot be used to determine the average coordination environment and local structure of metals as can be accomplished with XAFS. XAFS does not require a crystalline sample, as is the case for diffraction studies.

Finally, our studies have also made new technological advances in that we have developed safe protocols for handing these hazardous radioactive materials at synchrotrons. To our knowledge, these are the first measurements of the local structural environment of $U$ and $\mathrm{Hg}$ in real HLW samples.

\subsection{ACKNOWLEDGEMENTS}

The authors thank J. Woicik (National Institutes of Standards and Technology), A. Ackerman (BNL), M. McAvoy (BNL), R. Zantopp (BNL), S. Khalid (BNL), N. Gmur (BNL), T. Dickinson (BNL), R. Casey (BNL), W. Rao (University of Georgia), T. Lanzirotti (University of Chicago), and W. Tamosaitis (SRTC) for their assistance, support and ideas. B. Attaway, N. Bibler, T. Fellinger, C. Crawford, K. Prettal, D. Healy, R. Blessing, and N. Gregory (all of SRTC) provided assistance in the identification and preparation of the sludge samples. Mr. T. McCoy and his co-workers (SRTC) expertly and expediently prepared the aluminum metal shielding boxes according to our specifications. P. MacKenzie and S.

Page 30 of 33 
Jurgensen (WSRC) helped with shipping these samples. Connie Pierce (WSRC) provided excellent health physics support in the laboratory.

\subsection{REFERENCES}

\footnotetext{
${ }^{1}$ Koningsberger, D. C. and Prins, R. (1988). X-ray Absorption: Techniques of EXAFS, SEXAFS and XANES, Wiley, New York.

${ }^{2}$ Stern, E. A. (1974). Theory of extended X-ray absorption fine structure. Phys. Rev. B10, 3027-3037.

${ }^{3}$ Barnes, M. J., Dworjanyn, L. O., Fink, S. D., Fondeur, F. F., Geeting, M. W., Hay, M. S., Swingle, R. F., and Wilmarth, W. R. (1998) Examination of the potential for formation of energetic compounds in dry sludge. WSRC-TR-98-00407. Westinghouse Savannah River Company.
}

${ }^{4}$ Hobbs, D. T., Barnes, M. J., Peterson, R. A. and Crawford, C. L. (1998). Radioactive testing results in support of the In-Tank Precipitation Facility. WSRC-TR-98-00070. Westinghouse Savannah River Company.

${ }^{5}$ Ressler, T. (1999). WinXAS. A Program for X-ray Absorption Spectroscopy Data Analysis under MS Windows.

${ }^{6}$ Newville, M., Livins, P., Yacoby, Y., Rehr, J. J. and Stern, E. A. (1993). Near-edge X-ray-absorption fine-structure of $\mathrm{Pb}-\mathrm{A}$ comparison of theory and experiment. Phys. Rev. B-Cond. Matter, 47, 1412614131.

${ }^{7}$ Sayers, D. E. and Bunker, B. A. (1988). In X-ray Absorption: Techniques of EXAFS, SEXAFS and XANES. Koningsberger, D. C. and Prins, R. (eds). Wiley, New York, Chap. 6.

${ }^{8}$ FEFF is a software package that was generated by researchers at the Univ. of Washington with DOE funding support. Access and use of this software is free within the DOE complex.

${ }^{9}$ Mustre de Leon, J., Rehr, J. J., Zabinsky, S. I. and Albers, R. C. (1991). Ab initio curved-wave x-rayabsorption fine structure, Phys. Rev. B44, 4146.

${ }^{10}$ Rehr, J. J. and Albers, R. C. (1990). Scattering-matrix formulation of curved-wave multiplescattering theory: Application to x-ray-absorption fine structure. Phys. Rev. B41, 8139.

${ }^{11}$ Rehr, J. J., Mustre de Leon, J., Zabinsky, S. I. and Albers, R. C. (1991). Theoretical X-ray absorption fine structure standards. J. Am. Chem. Soc. 113, 5135.

${ }^{12}$ Rehr, J. J., Zabinsky, S. I. and Albers, R. C. (1992). High-order multiple scattering calculations of xray-absorption fine structure. Phys. Rev. Let. 69, 3397.

${ }^{13}$ Stern, E. A., Newville, M., Ravel, B., Yacoby, Y. and Haskel, D. (1995). The UWAFS analysis package - Philosophy and details. Physica B. 208-209, 117-120.

${ }^{14}$ Moyes, L. N., Parkman, R. H., Charnock, J. M., Vaughan, D. J., Livens, F. R., Hughes, C. R. and Braithwaite, A. (2000). Uranium uptake from aqueous solution by interaction with goethite,

Page 31 of 33 
lepidocrocite, muscovite, and mackinawite: An X-ray absorption spectroscopy study. Environ. Sci. Technol. 34, 1062-1068.

${ }^{15}$ Hudson, E. A., Terminello, L. J., Viani, B. E., Denecke, M., Reich, T., Allen, P. G., Bucher, J. J., Shuh, D. K. and Edelstein, N. M. (1999). The structure of $\mathrm{U}^{6+}$ sorption complexes on vermiculite and hydrobiotite. Clays. Clay Min. 47, 439-457.

${ }^{16}$ Chisholm-Brause, C., Conradson, S. D., Buscher, C. T., Eller, P. G. and Morris, D. E. (1994). Speciation of uranyl sorbed at multiple binding sites on montmorillionite. Geochim. Cosmochim. Acta. 58, 3625-3631.

${ }^{17}$ Waite, T. D., Davis, J. A., Payne, T. E., Waychunas, G. A. and Xu, N. (1994). Uranium adsorption to ferrihydrate: Application of a surface complexation model. Geochim. Cosmochim. Acta. 58, 54655478 .

${ }^{18}$ Wersin, P., Hochella, M.F., Persson, J., Redden, G., Leckie, J. O. and Harris, D. W. (1994). Interaction between aqueous uranium(VI) and sulfide minerals: Spectroscopic evidence for sorption and reduction. Geochim. Cosmochim. Acta 58, 2829-2843.

${ }^{19}$ Bargar, J. R., Reitmeyer, R. and Davis, J. A. (1999). Spectroscopic confirmation of uranium(VI)carbonato adsorption complexes on hematite. Env. Sci. Technol. 33, 2481-2484.

${ }^{20}$ Sylwester, E. R., Hudson, E. A. and Allen, P. G. (2000). The structure of uranium(VI) sorption complexes on silica, alumina and montmorillonite. Geochim. Cosmochim. Acta. 64, 2431-2438.

${ }^{21}$ Lieser, K. H., Quandtklenk, S. and Thybusch, B. (1992). Sorption of uranyl ions on hydrous silicon dioxide. Radiochim. Acta 57, 45-50.

${ }^{22}$ Bargar, J. R., Reitmeyer, R., Lehnart, J. J. and Davis, J. A. (2000). Characterization of U(VI)carbonato ternary complexes on hematite: EXAFS and electrophoretic mobility measurements. Geochim. Cosmochim. Acta. 64, 2737-2749.

${ }^{23}$ Allen, P. G., Shuh, D. K., Bucher, J. J., Edelstein, N. M., Palmer, P. A., Silva, R. J., Nguyen, S. N., Marquez, L. N. and Hudson, E. A. (1996). Determinations of uranium structures by EXAFS: Schoepite and other U(VI) oxide precipitates. Radiochim. Acta 75, 47-53.

${ }^{24}$ Thompson, H. A., Brown, G. E. and Parks, G. A. (1997). XAFS spectroscopic study of uranyl coordination in solids and aqueous solution. Amer. Mineral. 82, 483-496.

${ }^{25}$ Allard, T., Ildefonse, P., Beaucaire, C. and Calas, G. (1999). Structural chemistry of uranium associated with $\mathrm{Si}, \mathrm{Al}, \mathrm{Fe}$ gels in a granitic uranium mine. Chem. Geol. 158, 81-103.

${ }^{26}$ Sturchio, N. C., Antonio, M. R., Soderholm, L, Sutton, S. R. and Brannon, J. C. (1998). Tetravalent uranium in calcite. Science 281, 971-973.

${ }^{27}$ Reeder, R. J., Nugent, M., Tait, C. D. and Morris, D. E. (2000). Uranyl incorporation into calcite and aragonite: XAFS and luminescence studies. Enviro Sci Technol. 34, 638-644.

Page 32 of 33 
${ }^{28}$ Teo, B. K. (1986). EXAFS: Basic Principles and Data Analysis. Inorganic Chemistry Concepts, Vol. 9, Springer-Verlag. Berlin.

${ }^{29}$ Duff, M. C., Hunter, D. B. and Coughlin, J. U. (2000). Sample characterization of palladium supported on tetraphenylborate ERDA-GA005711 Report to Savannah River Technology Center. Nov. 2000.

${ }^{30}$ Wyckoff, R. W. G. (1963). Crystal Structures, Vol. 1, John Wiley \& Sons, New York, London. 